\title{
فاعلية الإرشاد الجمعي المستند إلى البرمجة اللفوية العصبية في تنمية \\ الصفات السلوكية ومهارات الاتصال اللفظي
}

\author{
* برهان حمادنة و راقع القحطاني
}

تاريخ قبوله 2019/10/20

تاريخ تسلم البحث 2019/4/21

The Effectiveness of Group Counseling Based on NeuroLinguistic Programming (NLP) in Developing the Behavioral Characteristics and Verbal Communication Skills

Burhan Hamadneh and Ragea Alqahtani, University of Najran, Kingdom of Saudi Arabia.

Abstract: This study examined the effectiveness of a group counseling program based on Neuro-Linguistic Programming (NLP) in developing the behavioral characteristics and verbal communication skills among outstanding students at Najran University. A quasi- experimental research design with onegroup pretest-posttest was used. The study sample consisted of 12 outstanding students enrolled at the faculty of education, Najran University in Saudi Arabia. A group counseling program based on Neuro-Linguistic Programming was developed. It consisted of (14) indicative group sessions; (60) minutes each. The duration of training applying the program of the study's sample lasted for four weeks, as the behavioral characteristicand verbal communication scales were used. Results indicated that there were statistically significant differences between mean scores of the experimental group in the pre-post test on the scales of behavioral characteristics and verbal communication, in favor of the posttest. This confirms the effectiveness of group counseling program in enhancing behavioral characteristics and verbal communication among outstanding students.

(Keywords: Group Counseling, Neuro-Linguistic Programming (NLP), Behavioral Characteristics, Verbal Communication, Outstanding Students, Najran University)

وقد بدأ الاهتمام بالحاجات الإرشادية للطلبة المتفوقين متأخرًا ثلاثة

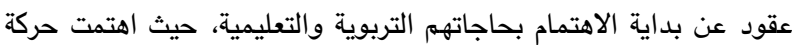

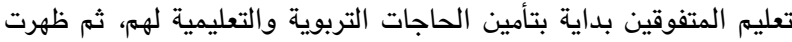

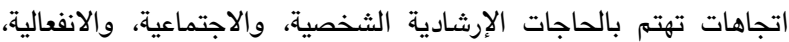

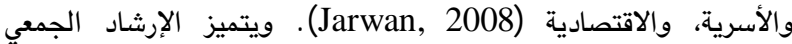

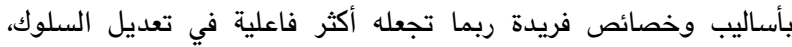

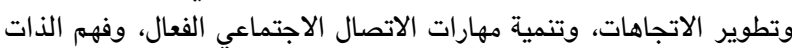

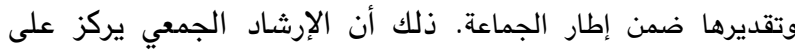

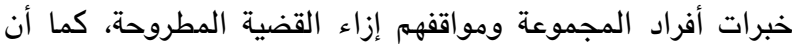

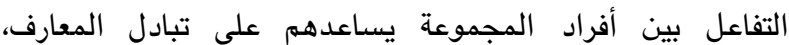

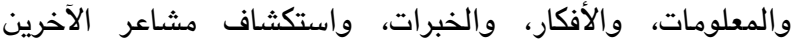

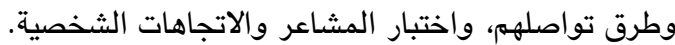

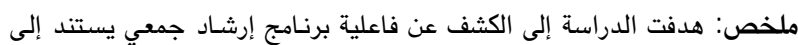

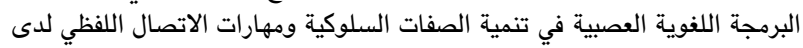

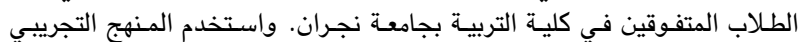

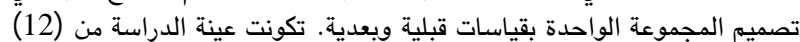

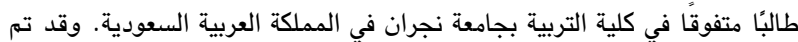

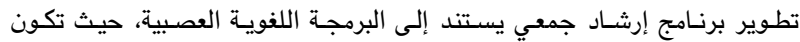

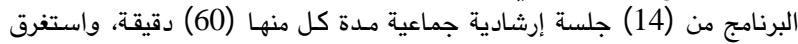

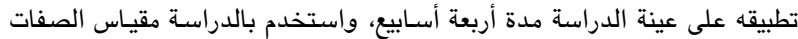

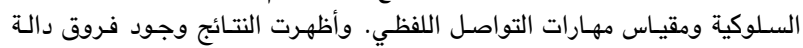

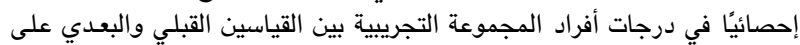

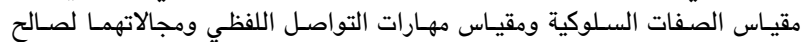

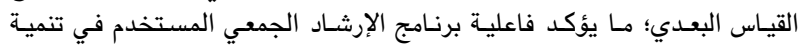
الصفات السلوكية ومهارات الاتصال اللفظي لدى الطيج الارثال الجاب الجامعيين المتفوقين.

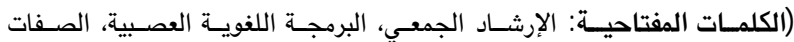
السلوكية، مهارات الاتصال اللفظي، الطلبة المتفوقين، جامعة نجران البردية

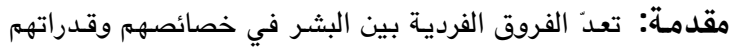

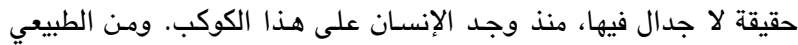

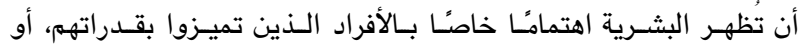

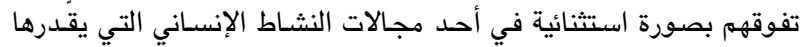

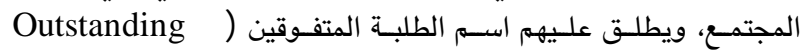

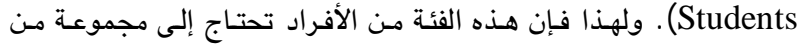

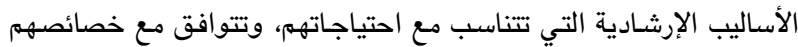

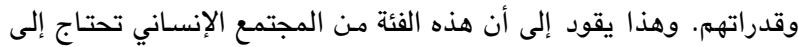

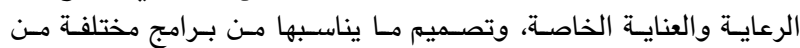

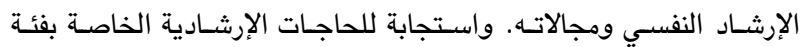

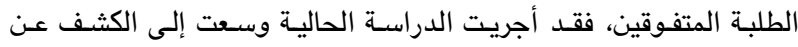

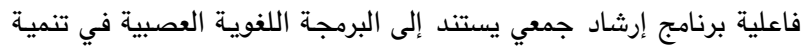

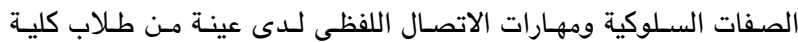
التربية المتفوقين في جامعة نجران بالمملكة العربية السعودية.

ويستند إرشـاد المتفوقين إلى ما يسمى الحاجة الإرشـادية، وتمثل

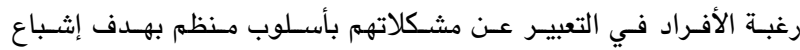

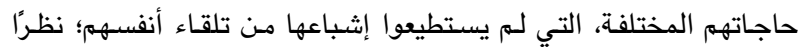

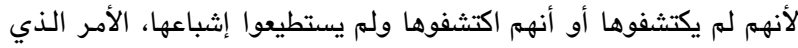

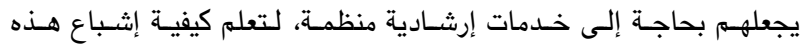

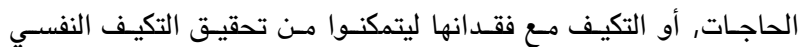

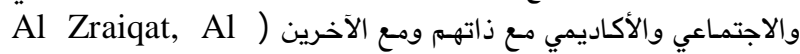

.(Rehani \& Tanous, 2010

$$
\text { † حقوق الطبع محفوظة لجامعة - المملكة العربية السعودية. . }
$$


فاعلية الإرشاد الجمعي في تنمية مستوى مفهوم الذات الاجتماعية لدى عينة من الطلبة الجامعيين.

Neuro Linguistic ) وقد نشأت البرمجة اللغوية العصبية كعلم مستقل في منتصف سبعينيات (Programming: NLP

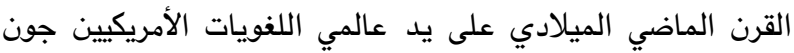

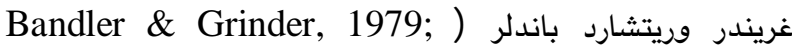

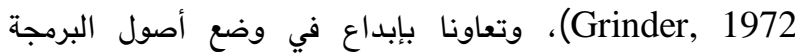

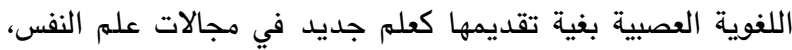

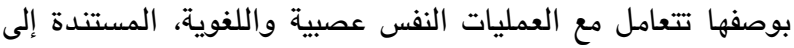

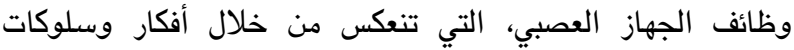

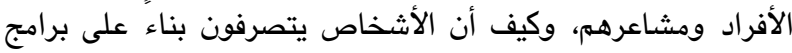

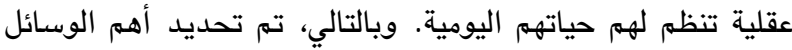
والنماذج السلوكية الناجحة التي يتبعها المعالجون النفسيون الذين

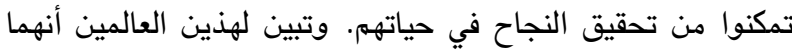

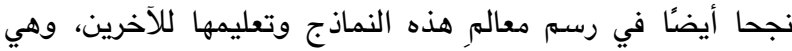
النماذج التي سميت فيما بعد بنماذج البرمجة اللغوية العصبية

.(Qandeel, 2012)

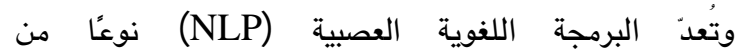

الاستراتيجيات المحايدة، تحافظ على تأمل الذات، حتى أثناء

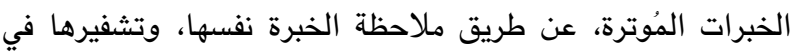

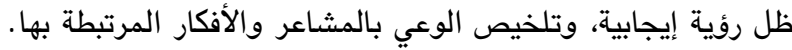

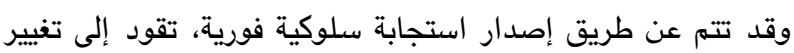

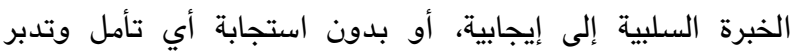

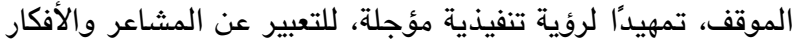

المرتبطة بها ضمن غايات مقصودة (Patterson, 1981).

وتتضمن البرمجة اللغوية العصبية (NLP) المفاهيم الثلاثة

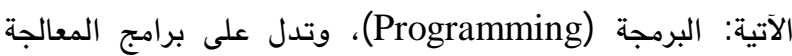

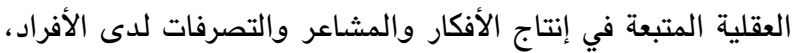

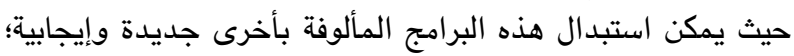

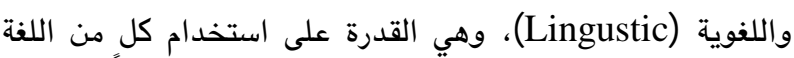
المحكية وغير المحكية، وتثير الأولى إلى كيفية عكس كلمات معينة ومجموعات من الكلمات لأحاديثنا ومفرداتنا العقلية، وتتناول الثانية الثانية الثانية

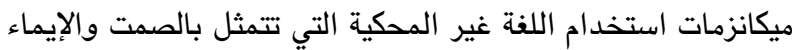
ولغة الوضعيات والحركات والعادات التي تكثف عن أساليبنا الفكرية

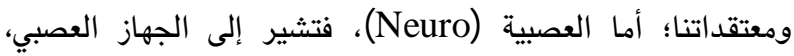

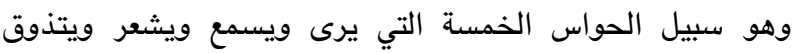
ويشم بها الفرد (Alfiky, 2009).

وتقوم البرمجة اللغوية العصبية على مجموعة من الافتراضات،

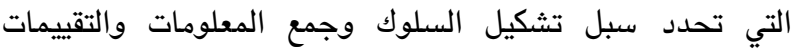

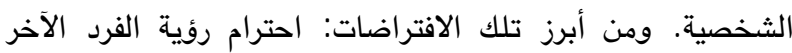

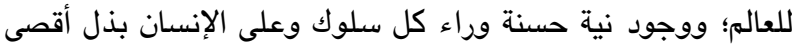

وتستخدم أساليب الإرشاد الجمعي بصورة خاصة في معالجة

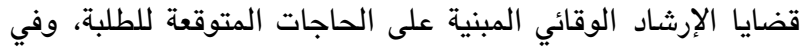

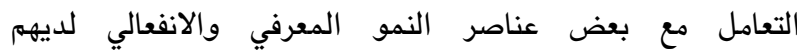
...(Hamadneh, 2014)

وعلى الرغم من أن الطلبة الجامعيين المتفوقين يحققون

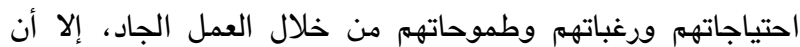

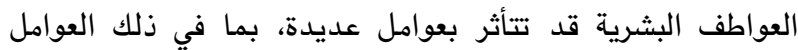

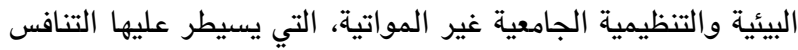

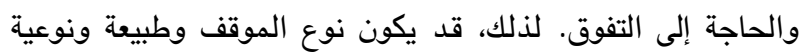
الجهد المطلوب لتحقيق التفوق من بين الضغوطات الرئيسية التي

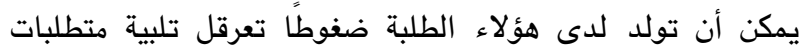
بعض الجوانب الثخصية والاجتماعية المفترض تأديتها في هذه تالهات

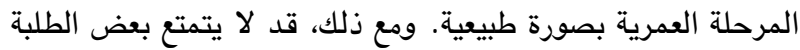

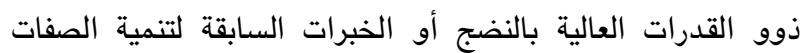

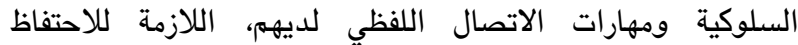

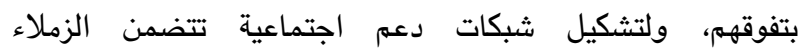

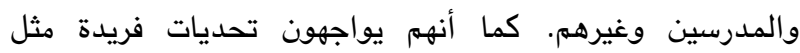
تعرضهم لزيادة وتيرة التنمر ضدهم (20remy, \& Fisher, )

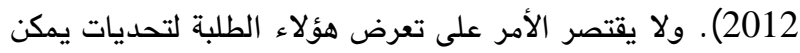

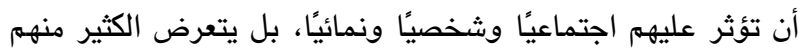

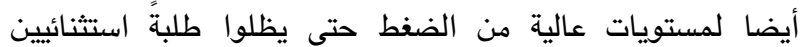

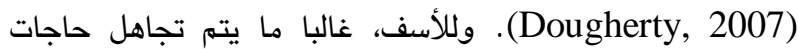
هؤلاء الطلبة في عملية تقديم الإرشاد النفسي والأكاديمي، لأنهم

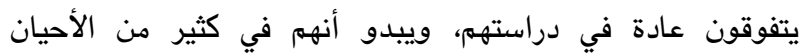

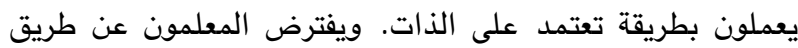
الخطأ أن الطلبة المتفوقين لا يحتاجون إلى الكثير من التوضئ التويهات،

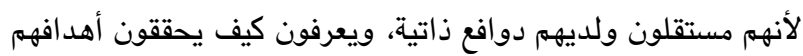
.(Glennen \& Martin, 2000)

ونظرًا لارتباط الدراسة الحالية بالحاجات لدى الطلبة المتفوقين، والحاجة إلى توفير برامج خاصة لتعليمهاط وتدريههم، والحاجة إلى تنمية الصفات السلوكية ومهارات الاتصال التهال اللفظي

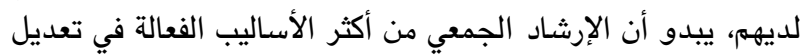

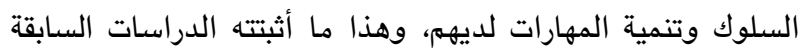

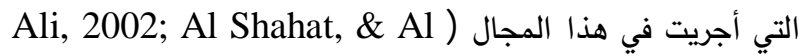

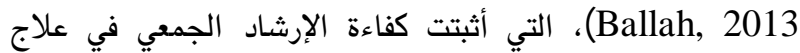

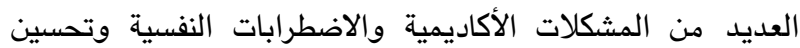

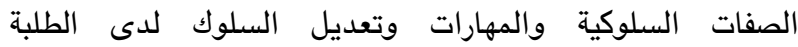
Abdel Wahab, ) الجامعيين. كما كثفت بعض الدراتهات (2010; Al Awwawi, 2004; Hamadneh, 2017

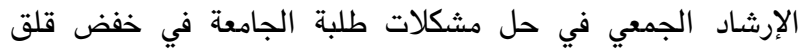
الاختبار وتحسين عادات الاستذكار لدى عينة من الطلبة المتفوقين في الجامعة. كما بينت دراسة السفاسفة (Al Safasfeh, 2011) 


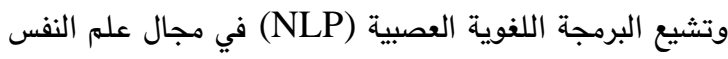

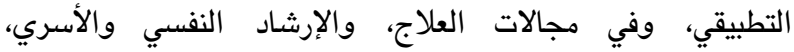

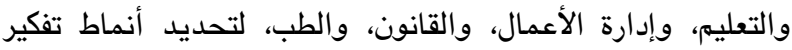

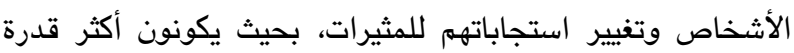

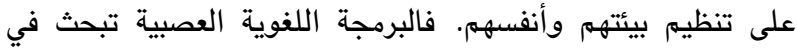
تحقيق الأهداف، وإنشاء علاقات مستقرة، وإزالة الحواجز النفسية والفية

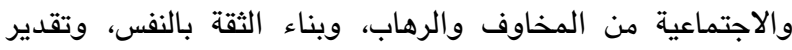

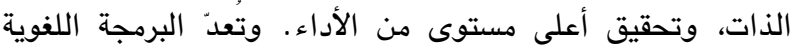

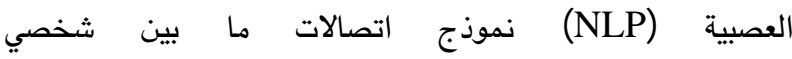
(Interpersonal communications model) الاعتقاد بأن اللفة تكون مرتبطة بقوة بالعمليات العصبية وأنماط

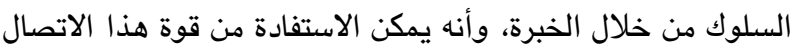

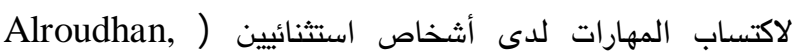
2018). كما يشمل العلاج النفسي اللفوي العصبي (Neuro-) (Linguistic Psychotherapy (NLPt) في علاج الأفراد الذين يعانون من مشكلات نفسية و/ أو اجتماعية مختلفة (Zaharia, Reiner \& Schutz, 2015).

ويتسم معظم الطلبة المتفوقين بمجموعة من الصفات السلوكية، يمكن تلخيصها بأربع صفات هي:

أولاً: الصفات الإبداعية: وتبدو من خلال حب المتفوقين للاستطلاع

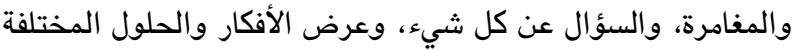

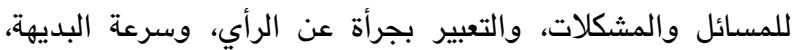

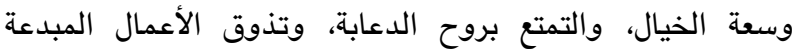

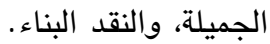

ثانيًا: الصفات القيادية: وتتضح في كفاءة المتفوقين في تحمل المسؤوليات، والتحدث بثقة وجرأة أمام الآخرين، ونشر المحبة بين زملائهم وألفة الآخرين، والتعبير عما يدور في خاطرهم بوضوح، واته

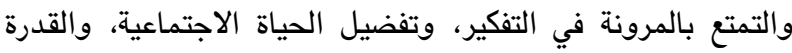
على إدارة الأنشطة التي يشاركون بها؛ والهيمنة على من حولهم،

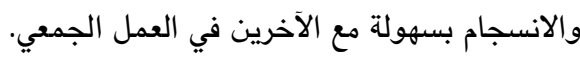
ثالثًا: الصفات الدافعية: وتظهر من خلال قدرة المتفوقين على إتقان العمل وحرصهم على إتمامه، أو الانزعاج من الأعمال الروتينية؛

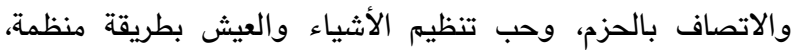
والتفريق بين الأشياء الحسنة والسيئة.

رابعًا : الصفات التعلمية: وتتمثل في امتلاك المتفوقين حصيلة لغوية تفوق مستوى عمرهم، وامتلاك حصيلة كبيرة من المعلومات في

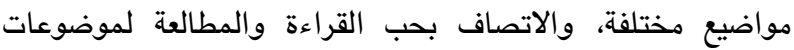
تفوق مستوى عمرهم، وسرعة وقوة الذاكرة، والقدرة على تحليل

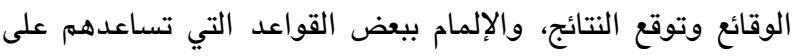
الاستنتاج، ورؤية الأمور والقضايا من زوايا مختلفة، وقياس ولاس وتحليل

الأمور المعقدة (Hamadneh, 2014).
ما يستطيع وفقا للمصادر المتوفرة لديه، ولا وجود لأشخاص

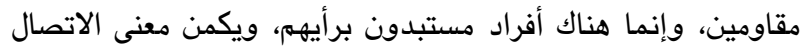

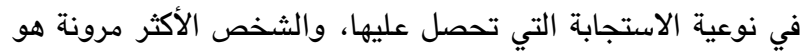

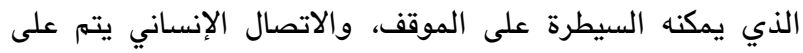

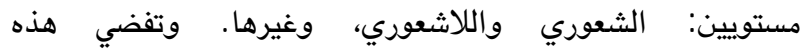

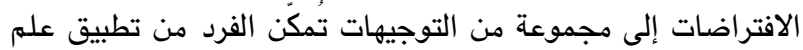
البرمجة اللغوية العصبية وتحقيق نتائج أكثر أهمية في حياته ( Al ( . (Farah, Bawalsah \& Al Khateeb, 2016

وتتضمن تدخلات العلاج النفسي بالبرمجة اللفوية العصبية

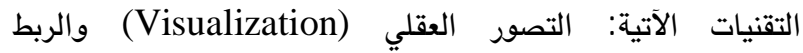
The Visual ) والتفكك الحسي البصري (Anchoring) Zaharia, Reiner \& ) (Kinesthetic Dissociation (Schutz, 2015

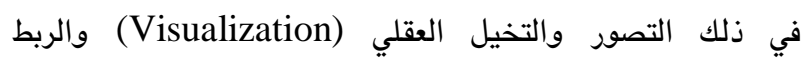
The Visual-) والتفكك الحسي البصري (Anchoring) (Kinesthetic Dissociation ومهارات تأكيد الذات، وتقنيات تغيير المعتقدات، وتقنيات إعادة وتداد

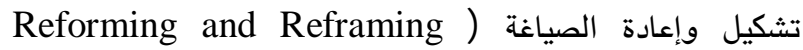
(Techniques Passmore \& ( ) والخريطة الذهنية وفهية (Sahebalzamani, 2014) Rowson, 2019 . ومثلما توفر أنماط اللفة نظرة ثاقبة عن (Sab) الطرائق التي يستخدمها المسترشدين، كذلك تفعل حركات العيون. وقد وضع باندلر وغريندر (Bandler \& Grinder, 1979) مصطلح إثارات العين الموصلة (Eye-accessing cues) بالنسبة لأولئك الذين يقومون بمعالجة المعلومات بشكل مرئي.

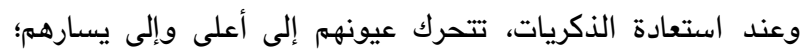

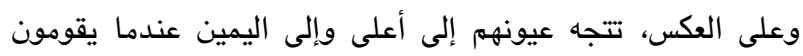

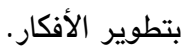

وتؤكد البرمجة اللفوية العصبية (NLP) على تطوير العلاقة وهي السياق الكلي الذي يدور حول الرسالة اللفظية،

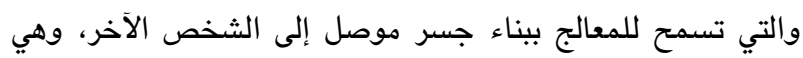

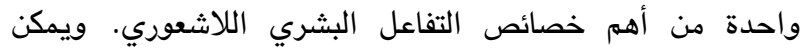

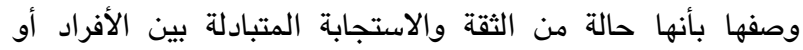

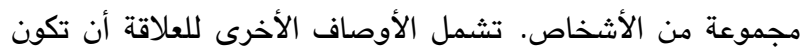
متزامنة، وأن تكون على نفس طول الموجة، وتثترك في المنظور

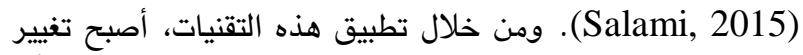
المعتقدات وتعديل السلوكيات غير المرغوبة والمجهدة أمرًا ممكنًا. فقد كان المسترشدون أكثر قدرة على التعامل مع المواقف العصيبة، من خلال تطبيق مهارات إدارة الوقت لتحقيق الرغبة الثخصية

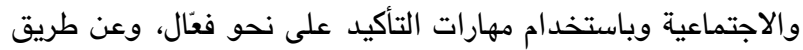

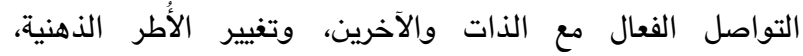

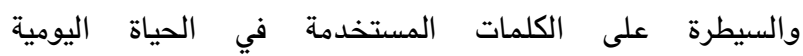
. (Sahebalzamani, 2014) 
وعن طريق إحدى وسائل الاتصال (Al Sayyed, 2010).

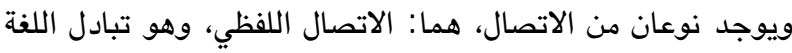

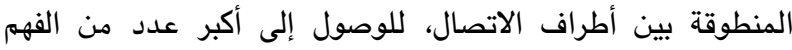

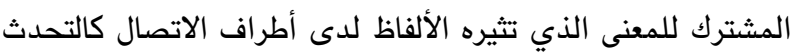

والقراءة والكتابة والاستماع (Bakheet \& Mustafa, 2010).

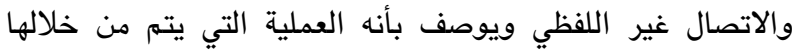

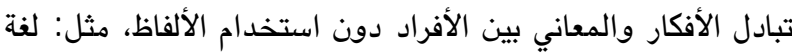

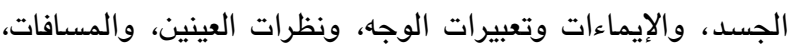
واللمس أو المصافحة، ونبرات الصوت (2015 Al Nsser, ) . (2015

وتضم عملية الاتصال اللفظي أربع من المهارات، هي: مهارة

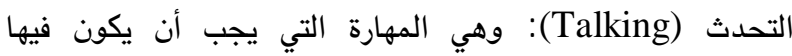

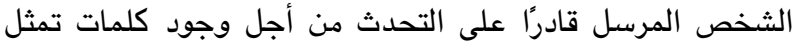

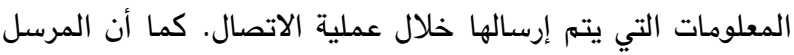

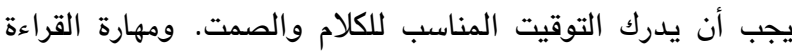
(Reading)

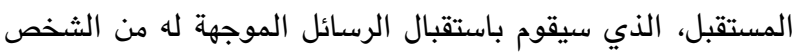

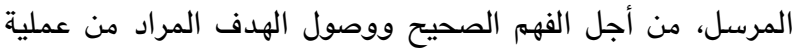

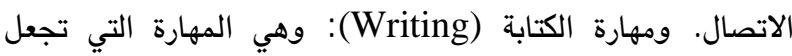

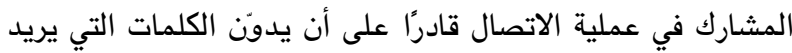

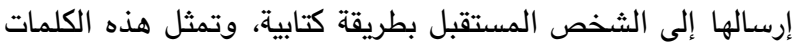

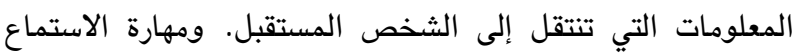
(Listening)

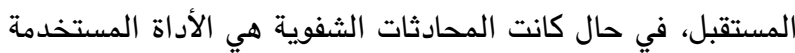

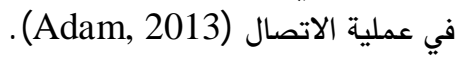

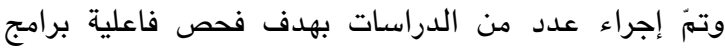

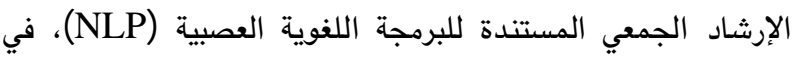

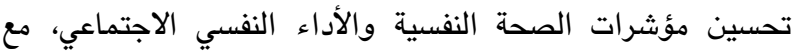
عينات متنوعة من المراهقين والشباب الجامعي؛ فقد أجرت عسلية

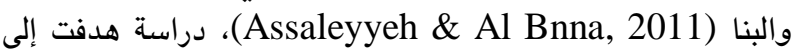

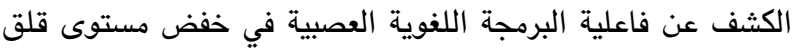

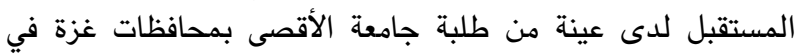

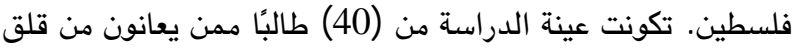

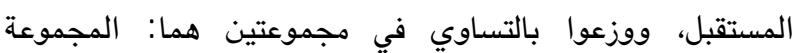

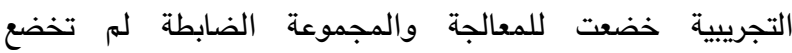

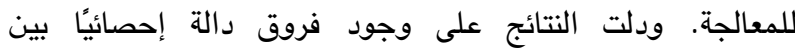

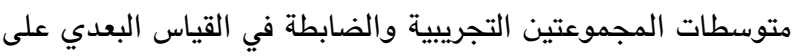
مقياس قلق المستقبل لصالح أفراد المجموعة التجريبية.

Bdaiwi \& Hussein, ) وهدفت دراسة بديوي وحسين

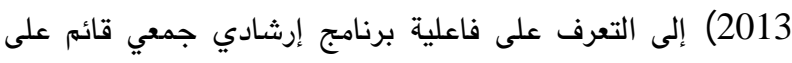

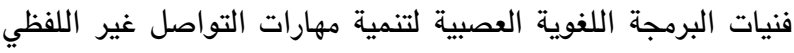

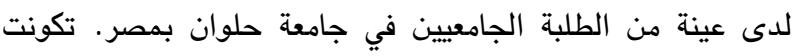

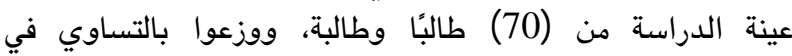

وتعدّ مهارات الاتصال للطالب الجامعي من المهارات الأساسية

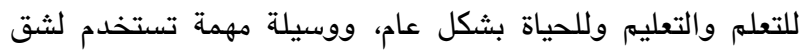

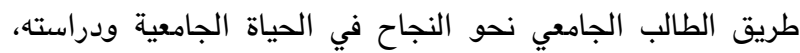

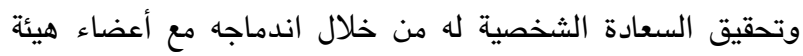
التدريس وزملائه في المحاضرات والأنثطة المنهجية واللامنهجية.

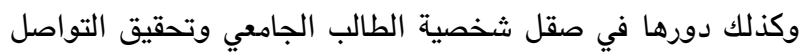

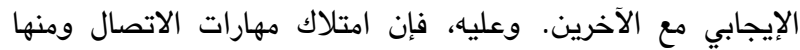

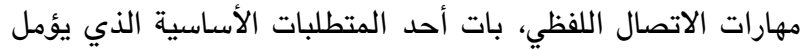

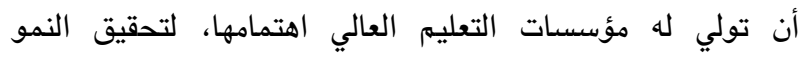

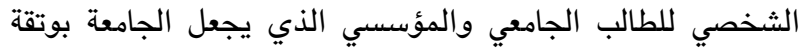

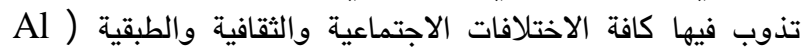
.(Ashqar, 2008

كما يعدّ الاتصال الإنساني جانبًا مهمًا في الحياة البشرية، فهو

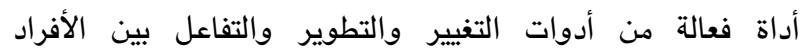

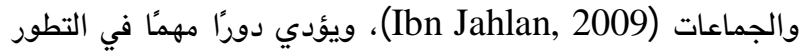

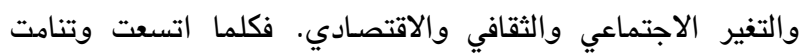
خطوات التغيير والتطور، اتسعت وازدادت الحاجة والتاني إلى المعلومات

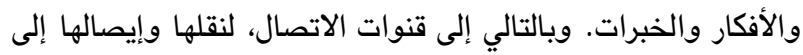

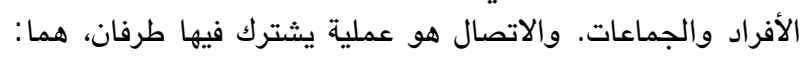

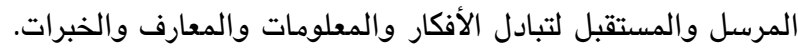

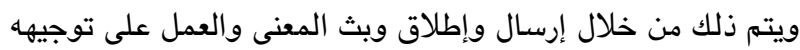

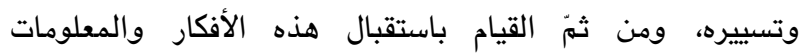

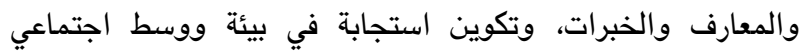

محدد (Abu Al Nsser, 2015).

وتتكون عملية الاتصال من خمسة عناصر رئيسة هي: المرسل (Sender/Encoder) : وهو الشخص الذي يبدأ بعملية الاتصال،

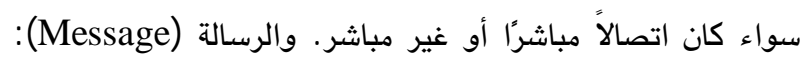

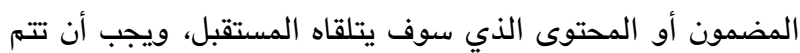

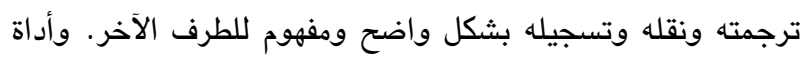
الاتصال (Medium): وهي وسيلة للاتصال بين الأطراف. والمستقبل (Receiver/Decoder): قد يكون المستقبل شخصًا

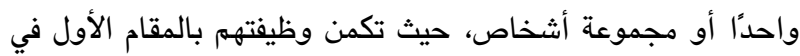
استقبال الفكرة التي يحاول المرسل إيصالها، وفهمها واستيعابها.

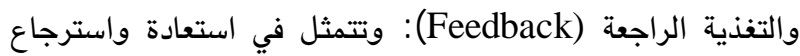
المستقبل للأفكار والمعلومات والمعارف والخبرات، ودرجة استفادته وتفاعله، ومدى تأثيرها عليه ) Al Sayyed, 2010; Suleiman, . (2014

ويحتاج تحقيق الاتصال الكفؤ إلى أن يمتلك الفرد مجموعة

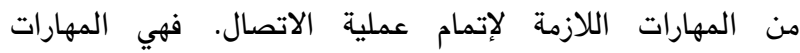

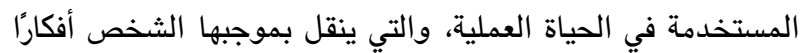

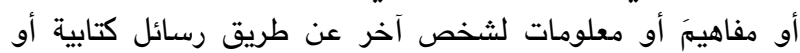

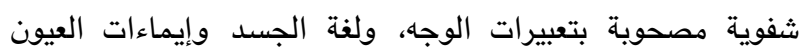


بمعدل وحدتين في الأسبوع، بلغت مدة كل وحدة (40-60)

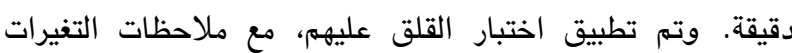

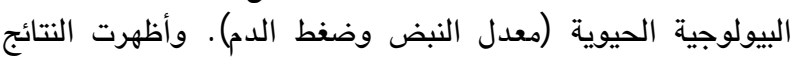

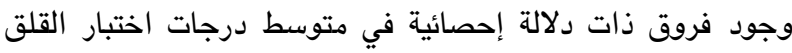

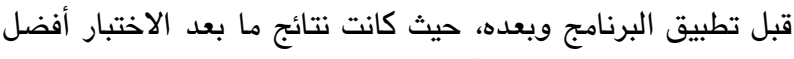

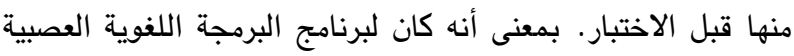

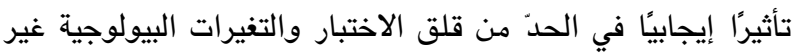

المرغوب فيها عند تطبيقها على المجموعة التجريبية.

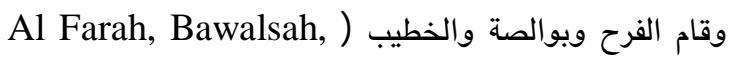
( \& Al Khateeb, 2016 فاعلية برنامج تدريبي قائم على البرمجة اللفوية العصبية (NLP)

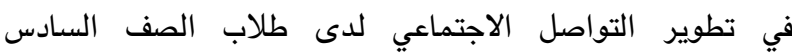

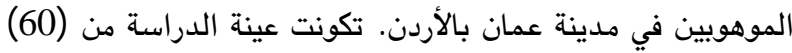

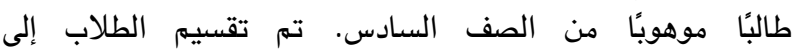

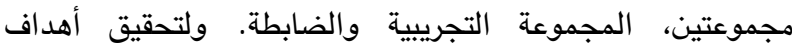

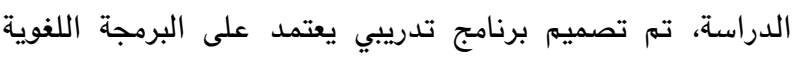

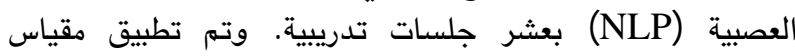

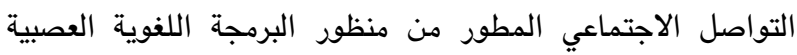

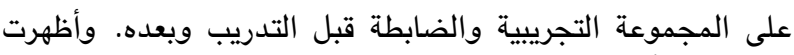

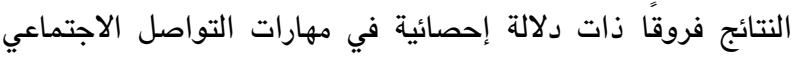

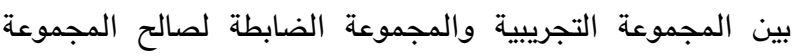

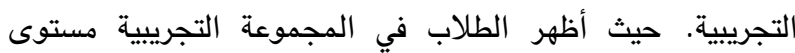
أفضل من استخدام مهارات التواصل الاجتماعي.

وقام الوليل (Al Waleel, 2016) بإجراء دراسة هدفت إلى في

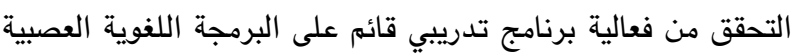

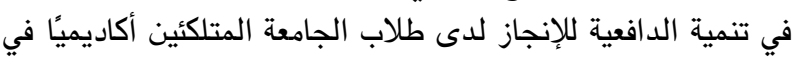

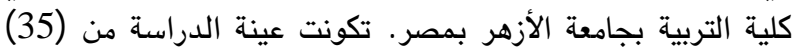

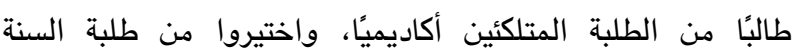

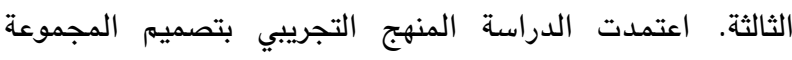

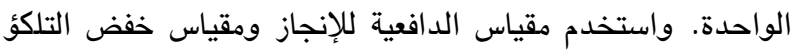

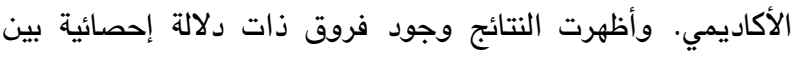

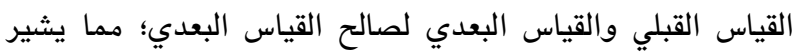

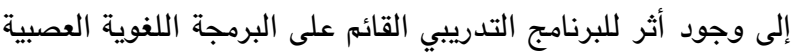

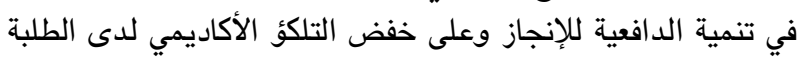
الجمامعيين.

وهدفت دراسة عبد الرحمن (Abdulrahman, 2018) إلى

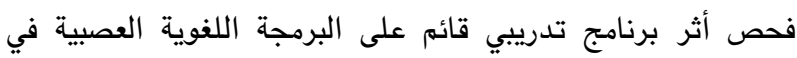

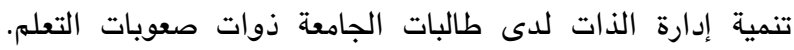

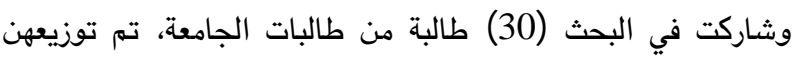

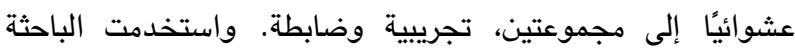

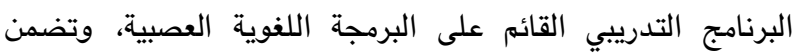

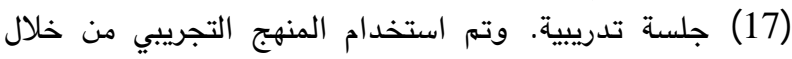

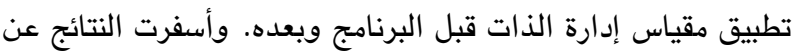

مجموعتين هما: المجموعة التجرييية خضعت للتدريب والمعالجة،

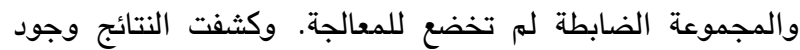

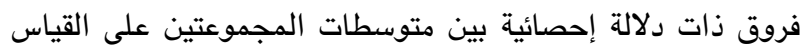

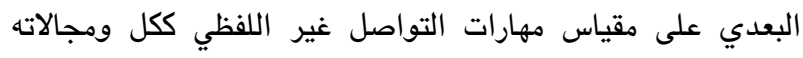
(مهارة تعبيرات الوجه، ومهارة حركة الجسمه، ومهارة المسافة بين التهاتين الأشخاص) لصالح أفراد المجموعة التجريبية.

وقام يوسف (Yousef, 2015) بإجراء دراسة هدفت إلى

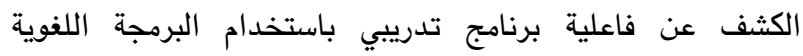

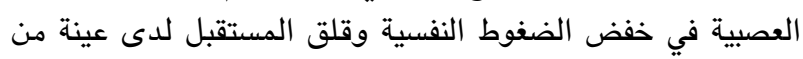
الطلبة المعلمين بجامعة القصيم في المملكة العربية السعودية.

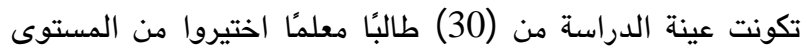

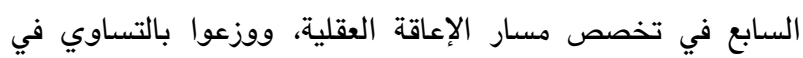

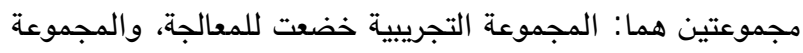

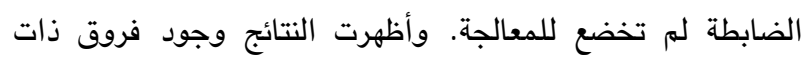

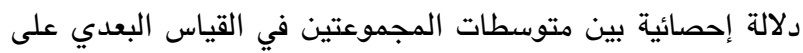

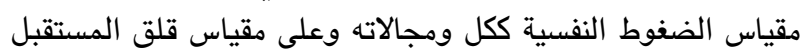
ككل ومجالاته لصالح أفراد المجموعة التجريبية. وأجرت سلامي (Salami, 2015) دراسة هدفت إلى تقييم أثر برنامج جمعي للتدريب على البرمجة اللغوية العصبية (NLP)

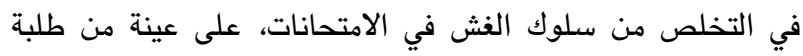

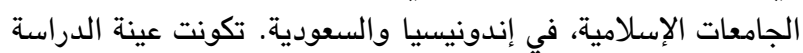

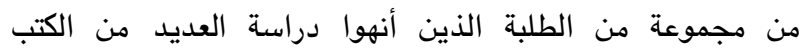

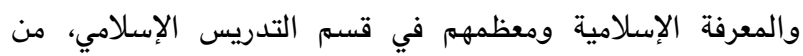

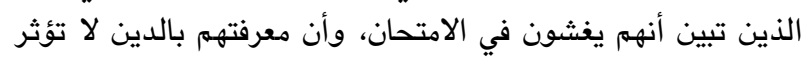

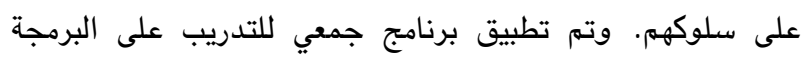

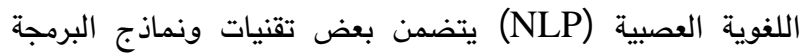

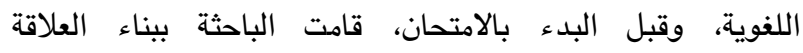

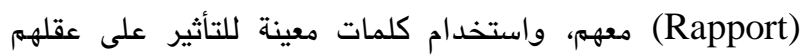

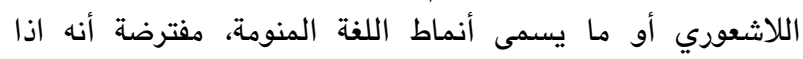

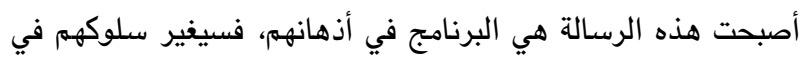

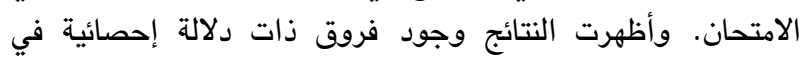

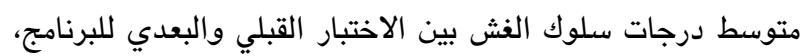

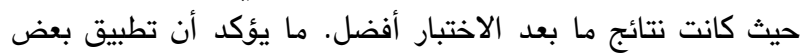

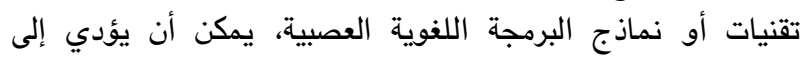

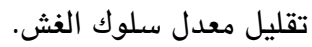

وأجرى فقيهي وحجاج (Fakehy \& Haggag, 2016) دراسة في جامعة الملك سعود، هدفت إلى الكثف عن أثر برنامج

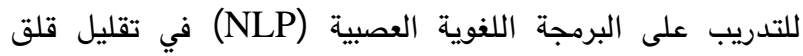

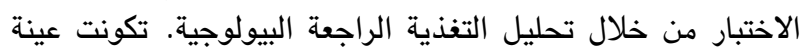

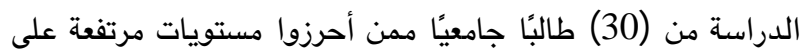

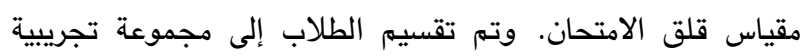

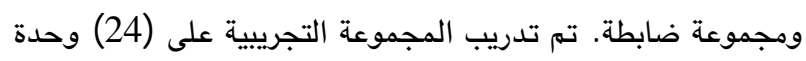
من استراتيجيات البرمجة اللفوية العصبية لمدة ثلاثة أشهر أي 


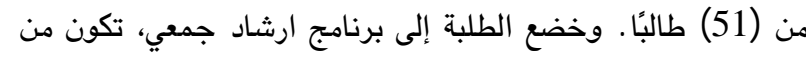

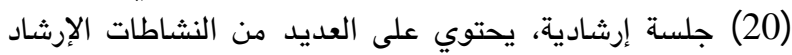

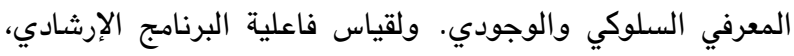

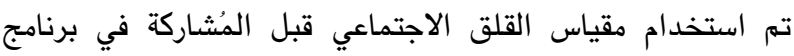

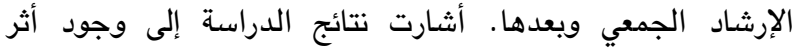

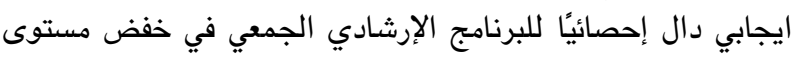
القلق الاجتماعي لدى طلبة الجامعة.

وسعت دراسة حمادنة (Hamadneh, 2017) إلى الكثف

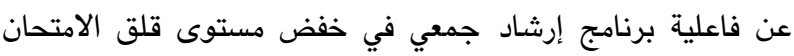
وتحسين عادات الاستذكار لدى عينة من الطلبة الجامعيين

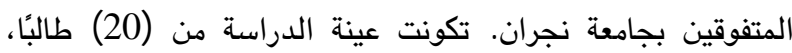

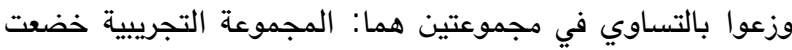

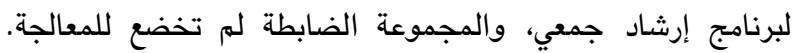

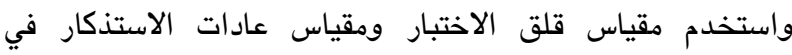

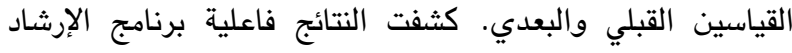

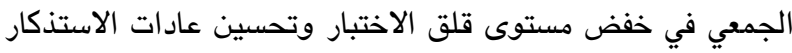
ل الدى أفراد المجموعة التجريبية.

وقامت أمودو وباساريلو وفاليريو وبوشيشو وسكاندورا

Amodeo, Picariello, Valerio, Bochicchio \& )

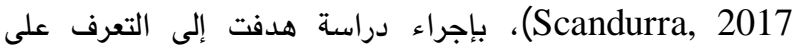

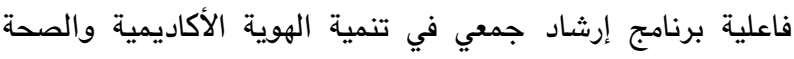

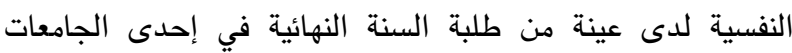

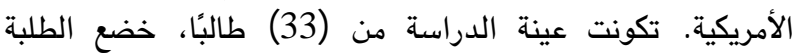

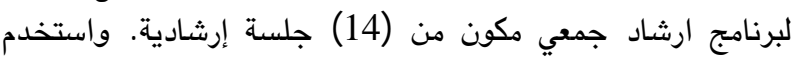

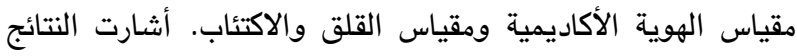
إلى فاعلية برنامج الارشاد الجمعي في تنمية الهية الهوية الأكاديمية الهابية الهابية وتخفيض مستوى القلق والاكتئاب لدى طلبة في السئة السنة النهائية في الهادية

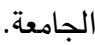

وبناء على ما سبق، تم استخدام البرمجة اللغوية العصبية

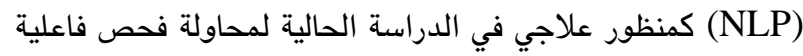

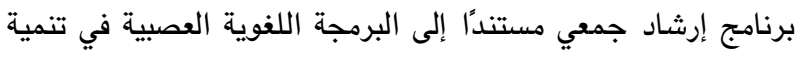

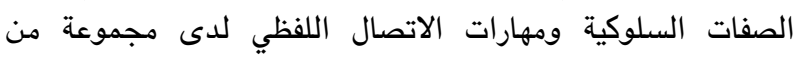

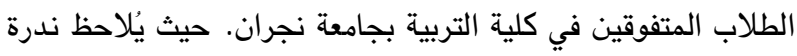

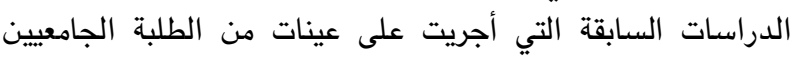

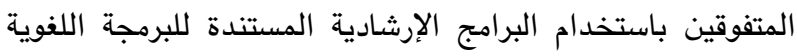

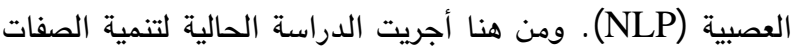

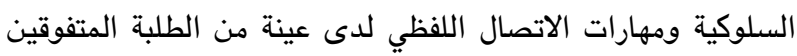

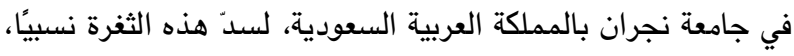

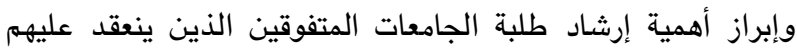

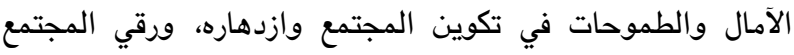

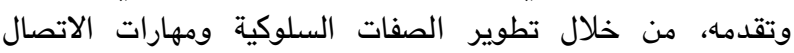
اللفظي لديهم، ما يساعدهم على الفهاتهم الحقيقي لقدراتهم وطاقاتهمه

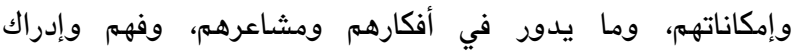

وجود فروق دالة إحصائيًا بين متوسطي الدرجات في القياسين

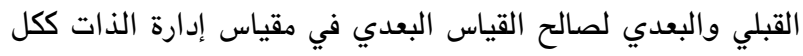

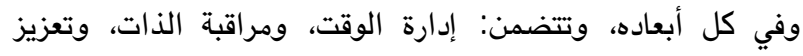

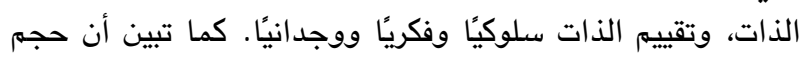

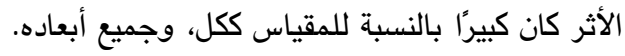
أما الدراسات التي أُجريت للكثف عن كفاءة برامج الإرشاد

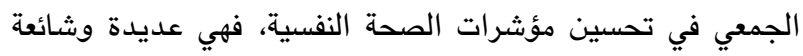

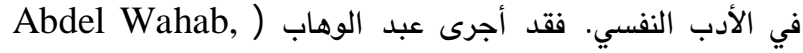

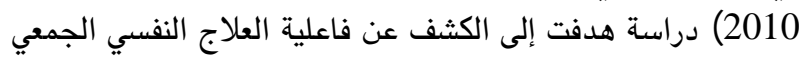

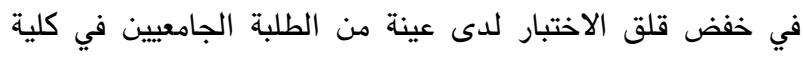

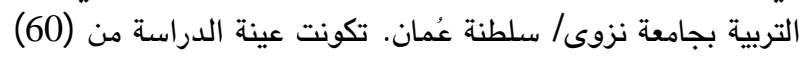

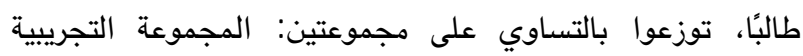

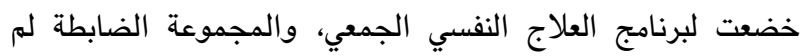

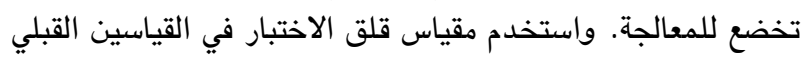

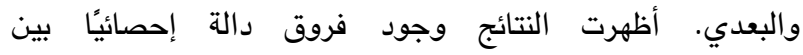

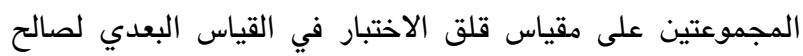

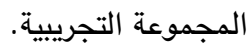

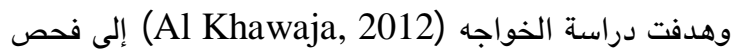

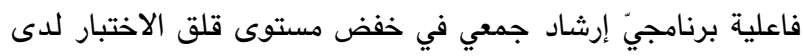

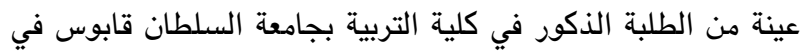

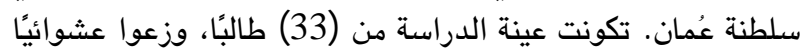

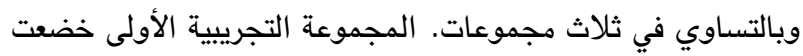

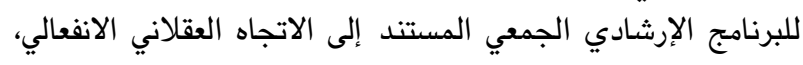

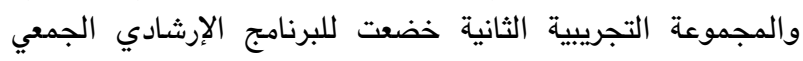

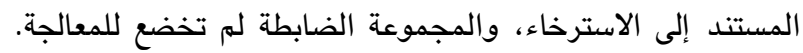

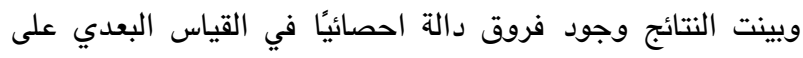

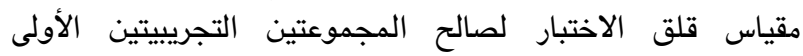

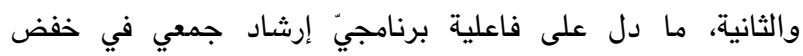

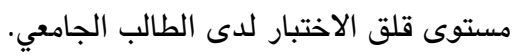

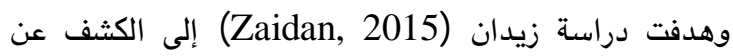

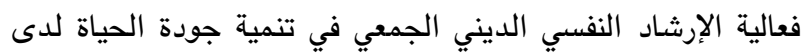

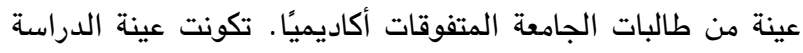

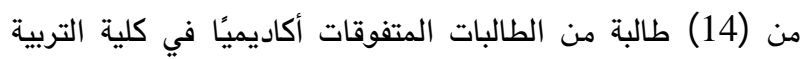

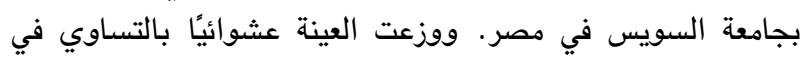

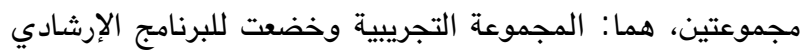

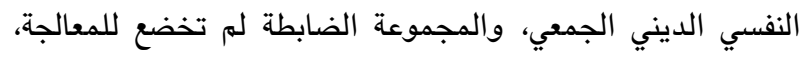

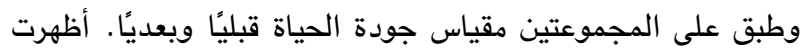

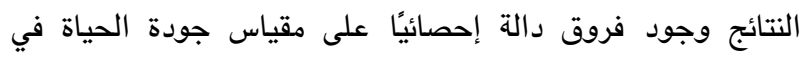
القياس البعدي، لصالح المجموعة التجريبية.

وقام أكاكان وسيسيم (Akacan \& Secim, 2015)

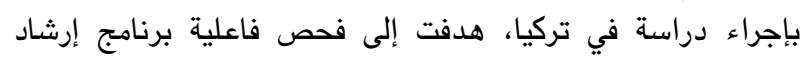

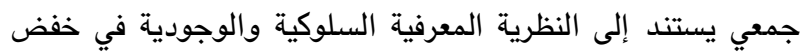
القلق الاجتماعي لدى عينة من طلبة الجامعة. تكونت عينة الدراسة المجية 
الفرضية الثانية: توجد فروق ذات دلالة إحصائية (

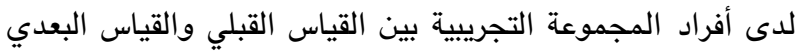
على مقياس مهارات الاتصال اللفظي لصالح القياس البعدي. أهمية الدراسة

نظرًا للدور الهام لبرامج الإرشاد الجمعي وفنيات البرمجة

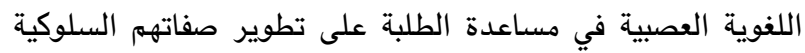

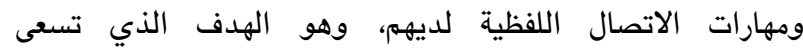

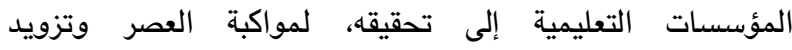
المجتمعات بأفراد متميزين قادرين على مسايرة التفاتئه التطور المعرفي

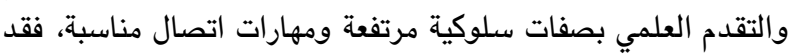

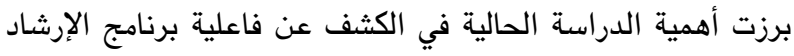

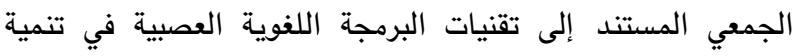
الصفات السلوكية ومهارات الاتصال اللفظي لدى عينة من الطلبة البردية

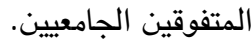

ومن المؤمل أن تسهم هذه الدراسة بما توفره من أدب نفسي تُوري

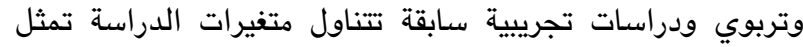

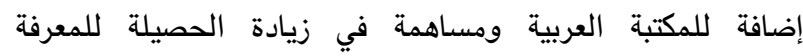

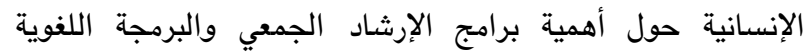

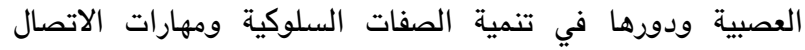
اللفظي لدى الطلبة المتفوقين الجامعيين، يمكن أن يكون ركية ركيزة

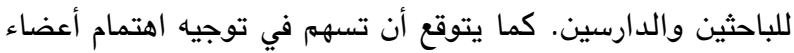

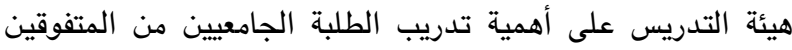

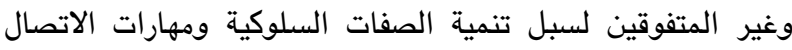

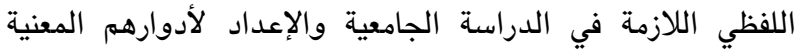

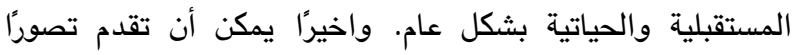

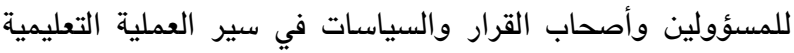

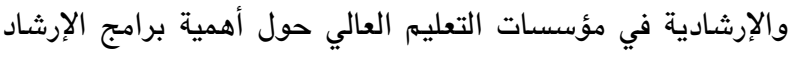

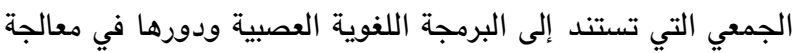

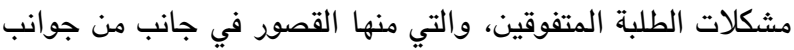

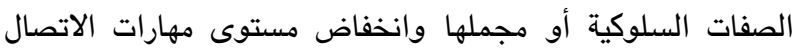

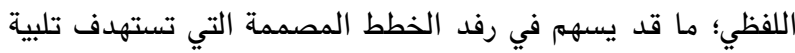
الحاجات الإرشادية للطلاب المتفوقين على المستويين المحلي

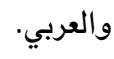
محددات الدراسة

اقتصرت الدراسة الحالية على الطلاب الجامعيين المتفوقين في

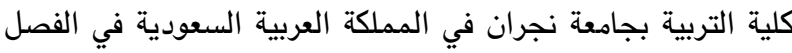

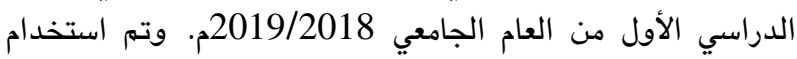
أداتين، هما: مقياس الصفات السلوكية ومقياس مهارات الاتصال التال السال

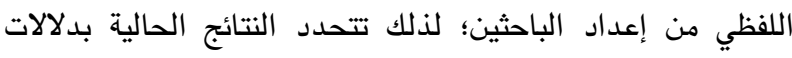

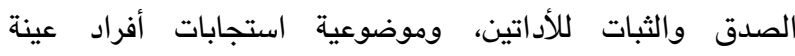

المعارف والمفاهيم والمعلومات والخبرات وما يدور حولهم من

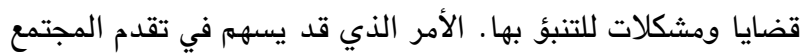
الإنساني العالمي والعربي بصفة عامة والمحلي بصفة خاصة.

مشكلة الدراسة وفرضياتها

انبثق الشعور بمشكلة الدراسة الحالية من خلال واقع خبرة

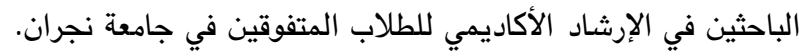

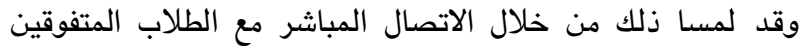

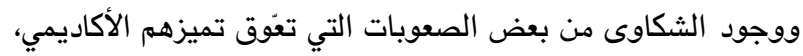

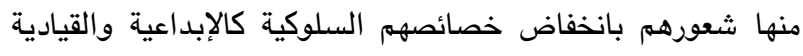

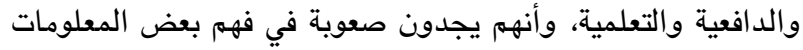

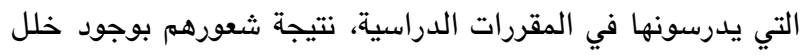

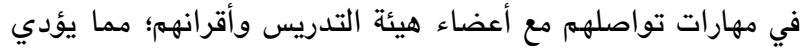

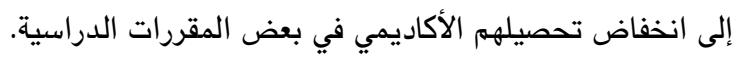
لذلك سعى الباحثان للبحث عن الأساليب الإرشادية الفعّالة

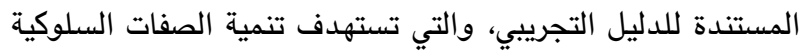

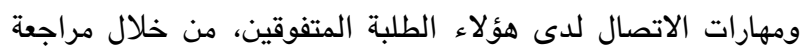

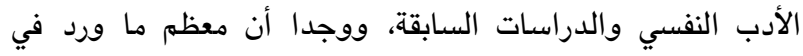

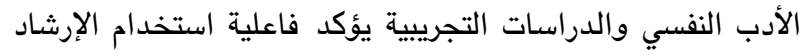

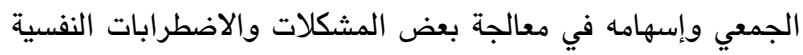

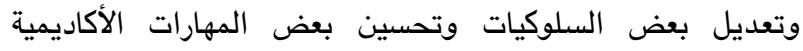
والاجتماعية والانفعالية لدى طلبة الجامعات، ومنها بعض الدئ الدراسات التي أجريت في البيئات العربية ( Al Khawaja, 2012; Al ؛(Safasfeh, 2011; Hamadneh, 2017; Zaidan, 2015 وفي البيئة الغربية (Dear et al., 2011)، وما يثبت أن استخدام

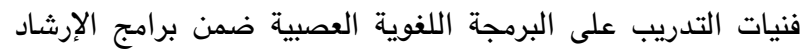

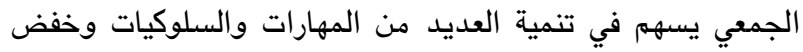

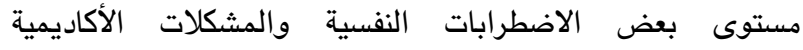
والاجتماعية والانفعالية لدى الطلبة الجامعيين ( Assaleyyeh \& Al Bnna, 2011; Al Waleel, 2016; Bdaiwi, \& . (Hussein, 2013; Yousef, 2015

وانطلاقًا من هذه المراجعة، وملاحظة الباحثين لندرة وجود

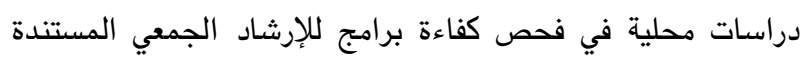

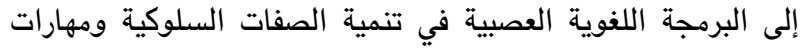

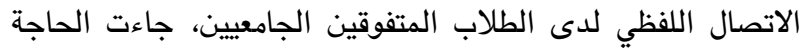

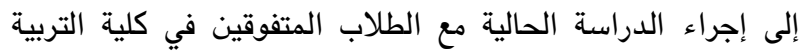

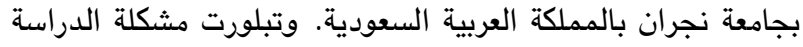
من خلال فحص الفرضيتين الفرعيتين الآتيتين:

الفرضية الأولى: توجد فروق ذات دلالة إحصائية (20.05

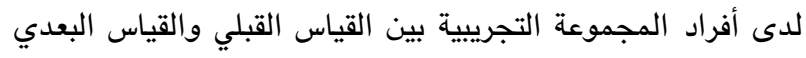

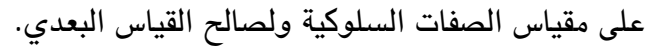




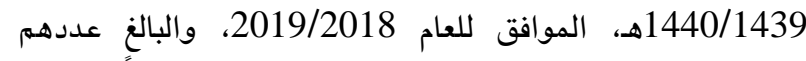
(14) طالبًا من الطلبة المتفوقين الذين حققوا معدلاً تراكميًا (GPA)

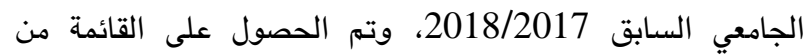
وحدة الإرشاد الأكاديمي في كلية التربية بجامعة نجران.

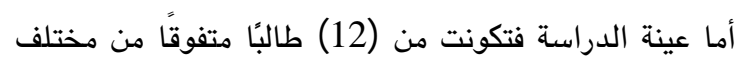

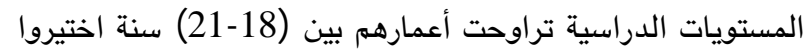

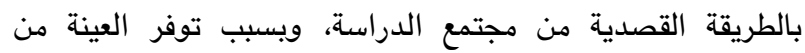

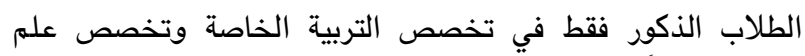

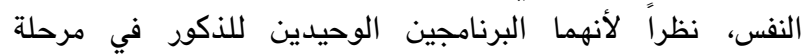

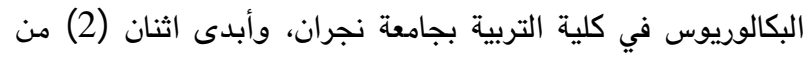
الطلبة عدم رغبتهما في المشاركة بالدراسة.

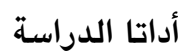

1. 1 مقياس الصفات السلوكية

Renzulli, Smith, ) استخدم مقياس رينزولي وآخرون

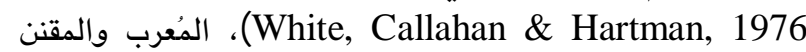

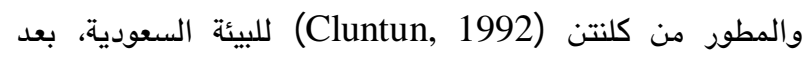

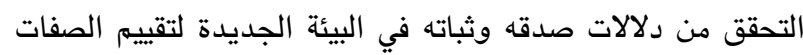

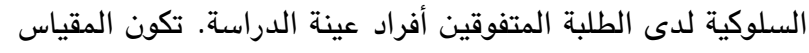

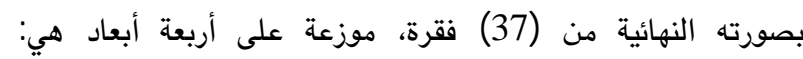

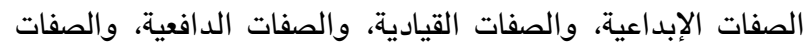

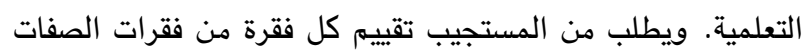

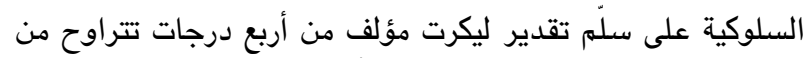

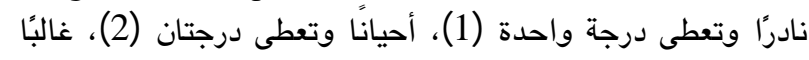

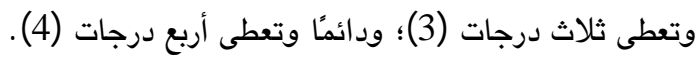

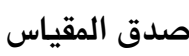

تم التحقق من صدق المحتوى لمقياس الصفات السلوكية

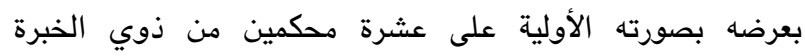

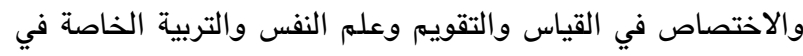

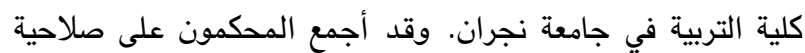

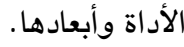

كما تم التحقق من صدق المقياس باستخدام صدق البناء .فقد

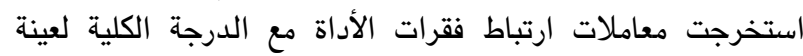

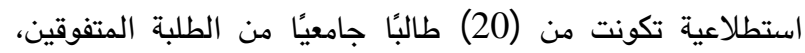

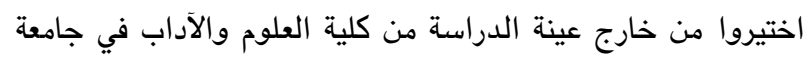

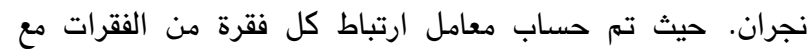
الدرجة الكلية من جهة، وبين كل فقرة والمجال الذي الدي تنتمي إليه،

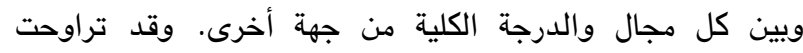

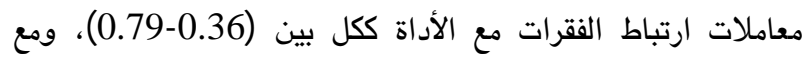

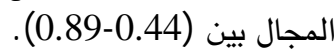

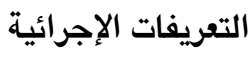

• برنامج الإرشاد الجمعي ( Counseling (Program

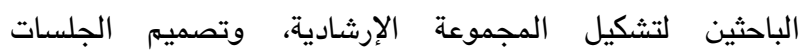

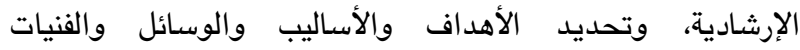

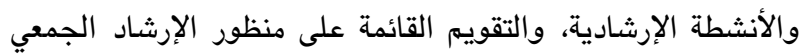

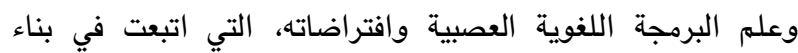

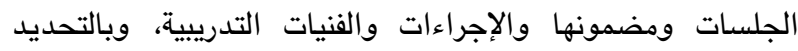

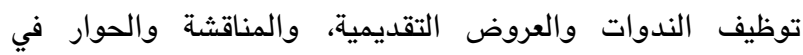

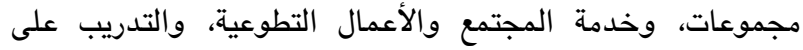
القيادة، لتحقيق أهداف الدراسة.

• Neuro-Linguistic ) البرمجة اللفوية العصبية والاسالي Programming: NLP

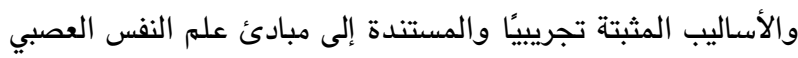

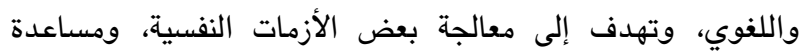

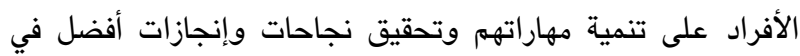

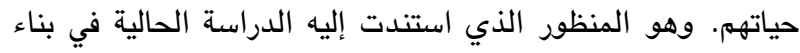

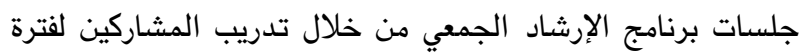

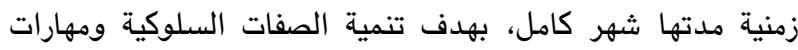
الاتصال اللفظي لدى عينة من الطلبة المتفوقين في كلية التربية بجامعة نجران بالمملكة العربية السعودية.

• الصفات السلوكية (Behavioral Charecterstics): مجموعة من الصفات السلوكية لدى الطلاب المتفوقين كالصفات

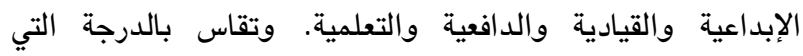

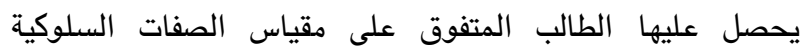
المستخدم في الدراسة الحالية. الئات

• مهارات الاتصال اللفظي ( Verbal Communication (Skills

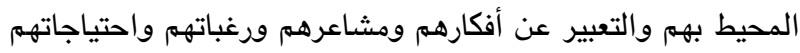

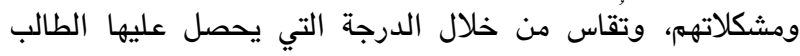

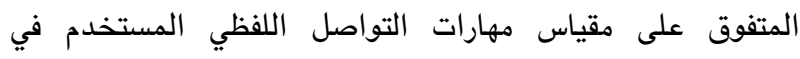

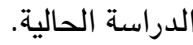

• الطلبة المتفوقون (Outstanding Students): مجموعة

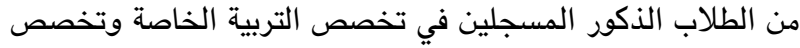

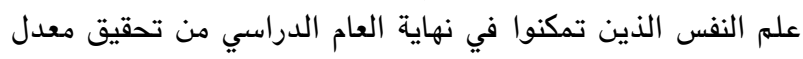

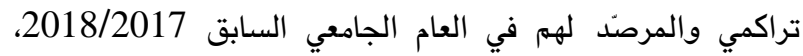
يتراوح من (4.10- 5) درجات من أصل (5) درجات كيد العد أعلى.

$$
\text { مجتمع الدراسة وعينتها }
$$

تكون مجتمع الدراسة من مجموع الطلاب المتفوقين في كلية التربية بجامعة نجران في الفصل الدراسي الأول من العام الجامعي الدي في كلية 


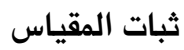

حساب معامل ارتباط بيرسون بين الدرجات على الأداة في مرتي

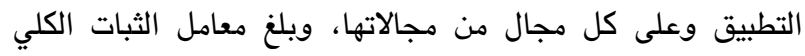

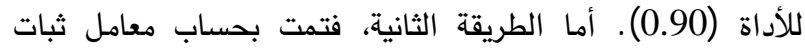
الاتساق الداخلي كرونباخ ألفا (Cronbach's Alpha) للأداة الأبات

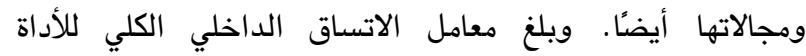
(0.84) ـ والجدول (1) يبين نتائج ذلك.
تم التحقق من ثبات مقياس الصفات السلوكية بطريقتين:

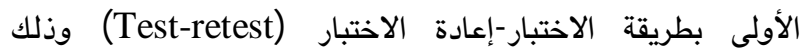

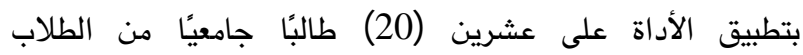

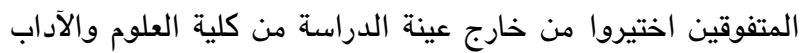

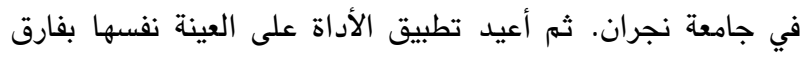
زمني مدته أسبوعان بين التطبيق الأول والتطبيق الثانيق الثاني. وتم

جدول (1): معامل ثبات الإعادة والاتساق الداخلي "كرونباخ ألفا" للأبعاد والدرجة الكلية لمقياس الصفات السلوكية

\begin{tabular}{|c|c|c|}
\hline "الاتساق الداخلي/ مرونباخ ألفا" معامل & معامل ارتباط "بيرسون" & المجال \\
\hline 0.74 & 0.88 & الصفات الإبداعية \\
\hline 0.73 & 0.91 & الصفات القيادية \\
\hline 0.71 & 0.87 & الصفات الدافعية \\
\hline 0.76 & 0.81 & الصفات التعلمية \\
\hline 0.84 & 0.90 & الأداة ككل \\
\hline
\end{tabular}

المقياس باستخدام صدق البناء من خلال استخراج معاملات ارتباط

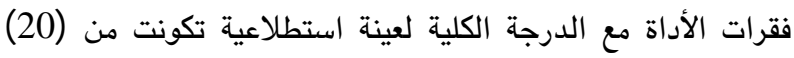

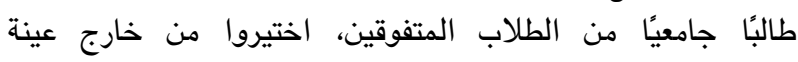

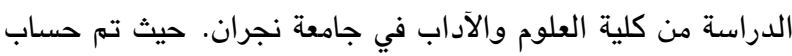

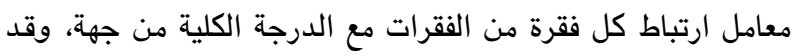

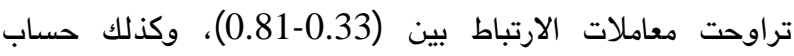
معامل ارتباط كل فقرة والمجال الذي تنتمي إلياط اليه، وتراوحت بين وكنات . (0.88-0.47)

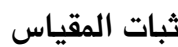

تم التحقق من ثبات مقياس مهارات الاتصال اللفظي بطريقة

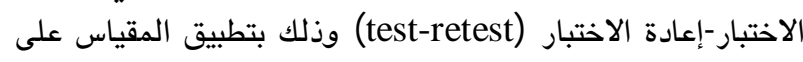

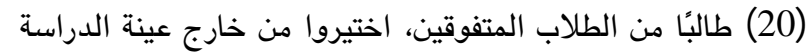

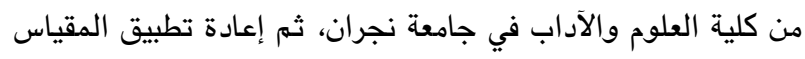

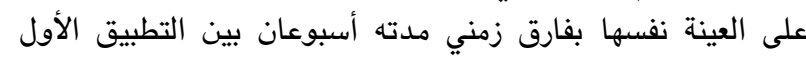

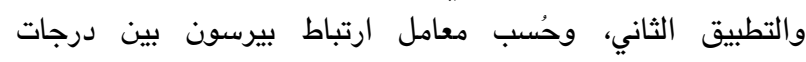

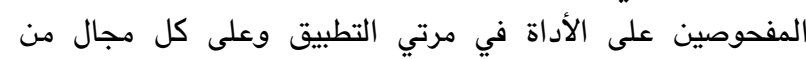

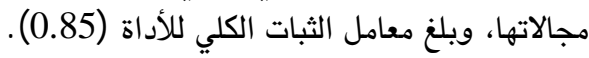

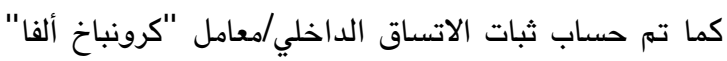

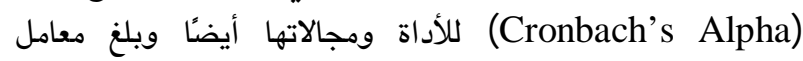
الاتساق الداخلي الكلي للأداة (0.82) . والجدول (2) يبين ذلك.
وبالنظر إلى القيم الواردة في الجدول (1) يُلاحظ أنها ذات

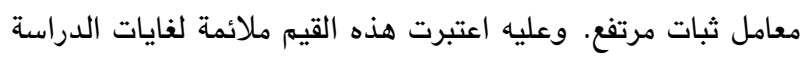

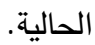

2. مقياس مهارات الاتصال اللفظي

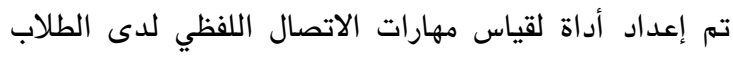

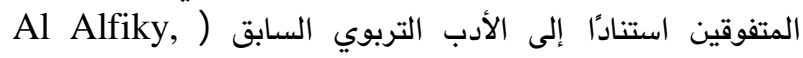

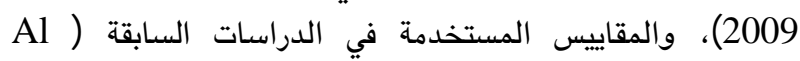

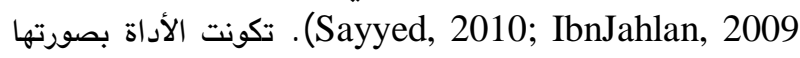

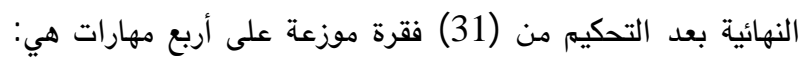

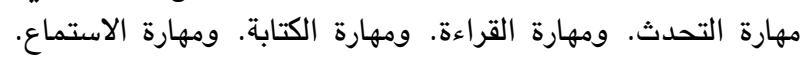

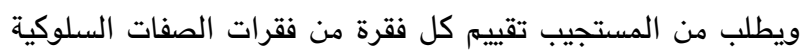

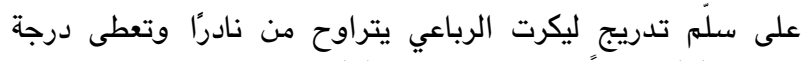

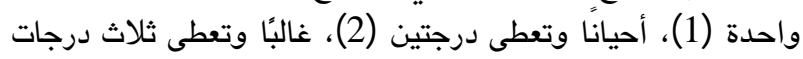
(3)؛ ودائمًا وتعطى أربع درجات (4) وتئل صدق المقياس تم التحقق من صدق مقياس مهارات الاتصال اللفظي بعرضه

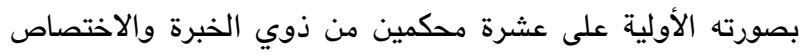

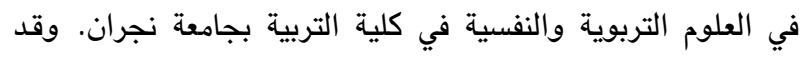

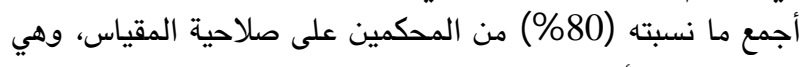

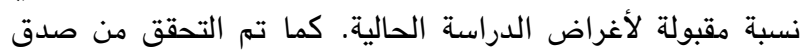


جدول (2): معامل ثبات الإعادة والاتساق الداخلي/ كرونباخ ألفا لمهارات الاتصال اللفظي والدرجة ككل

\begin{tabular}{|c|c|c|}
\hline "كرونباخ ألفا " الاتساق الداخلي معامل & معامل ارتباط "بيرسون" & المهارات \\
\hline 0.73 & 0.88 & مهارة التحدث \\
\hline 0.70 & 0.91 & مهارة القراءة \\
\hline 0.72 & 0.94 & مهارة الكتابة \\
\hline 0.70 & 0.84 & مهارة الاستماع \\
\hline 0.82 & 0.85 & الأداة ككل \\
\hline
\end{tabular}

البرنامج ومدى ملاءمته لأفراد عينة الدراسة وفي تحقيق أهداف افت الفاء

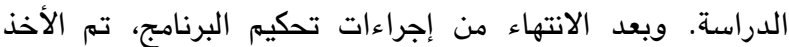

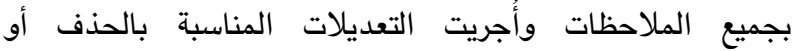
بالإضافة. وقد بلغت نسبة الاتفاق بين المحكمين (80\%) فأعلى العاحئ وهي نسبة مقبولة لأغراض الدراسة الحالية.

$$
\text { الهدف العام لبرنامج الإرشاد الجمعي }
$$

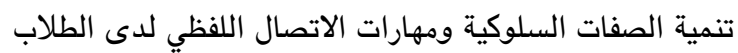
المتفوقين من أفراد الدراسة في المجموعة التجريبية. الأهداف الخاصة لبرنامج الإرشاد الجمي هدف البرنامج الحالي لتحقيق الأهداف الخاصة الآتية: تعرف

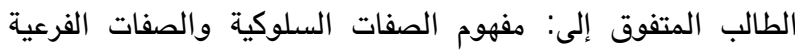

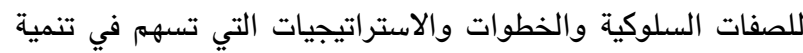
الصفات السلوكية، ومفهوم مهارات الاتصال والاتصال التال اللفظي.

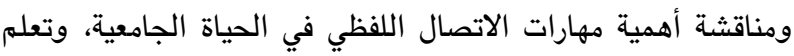

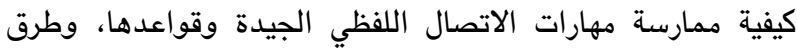

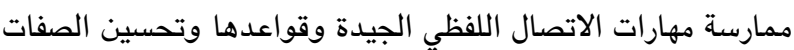
السلوكية لدى الطالب المتفوق في دراسته الجامعية وحياته. المسؤول عن تنفيذ البرنامج قام الباحثان بالإشراف المباشر على البرنامج والتدريب في

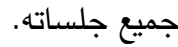

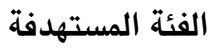
الطلاب المتفوقون دراسيًا في كلية التربية بجامعة نجران، وقد تراوحت أعمارهم بين (18-21) سنة. دور المرشد (الباحثان) تنفيذ جلسات البرنامج. وإدارة القاعة والندوات وجلسات الإرشاد الجمعي والأعمال التطوعية. ومساعدة الطلاب على التلى إخراج

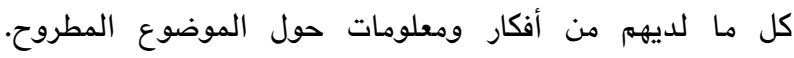

يلاحظ من الجدول (2) أن معاملات الثبات بالطريقتين

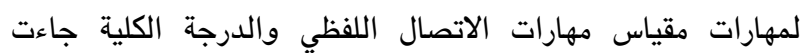

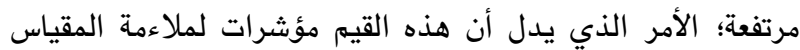
لفايات تحقيق أهداف الدراسة الحالية.

\section{برنامج الإرشاد الجمعي المستند إلى البرمجة اللفوية العصبية} اعتمد بناء برنامج الإرشاد الجمعي بصورة أساسية على (لئل

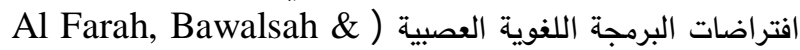
(Al Khateeb, 2016

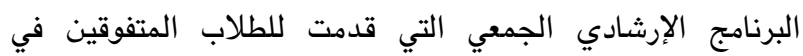

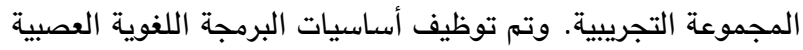

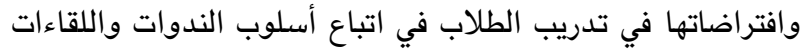

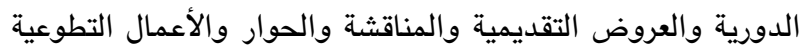

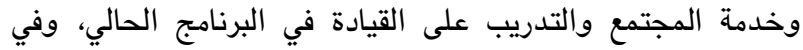
كيفية ترجمة الجلسات الإرشادية إلى جلسات إجرائية قابلة للتنفيذ التيا لئي

$$
\text { والتطبيق. }
$$

كما تمت الاستعانة بما ورد في الأدب النفسي، الذي تناول

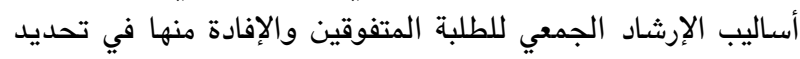
الأسلوب الأفضل في تدريب المتفوقين ( Abu Asa'ad, 2011 (Hamadneh, 2014a; Jarwan, 2012 على نماذج من برامج الإرشاد الجمعي المستخدمة في دراسات Al Khawaja, 2012; Abdel Wahab, 2010; Al ) سابقة فراتي (Shahat\& Al Ballah, 2013 Assaleyyeh \& Al Bnna, ) إلى البرمجة اللفوية العصبية (2011) 2011; Awad, 2016; Awad, 2016 تحديد مضمون جلسات البرنامج والوقت اللازم لتنفيذ كل جلسة

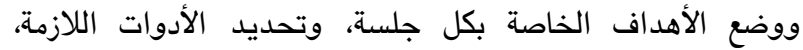

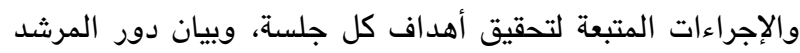
والمسترشد في الجلسة، وكيفية تقييم كل جلسة.

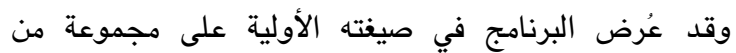

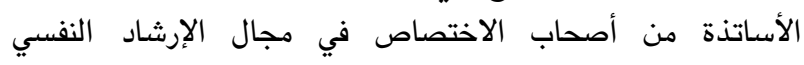

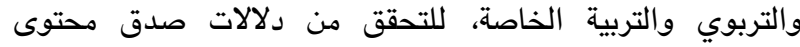


جلسات البرنامج ومدتها

تكوّن البرنامج في صورته النهائية من ثلاث جلسات رئيسة،

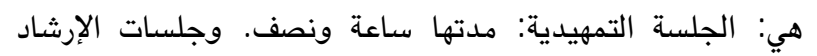

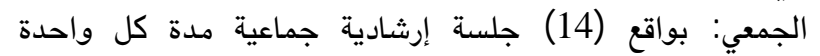

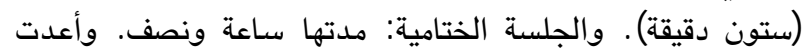

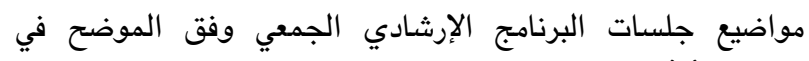

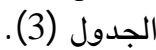

والترحيب بالأفكار المطروحة وعرضها على المجموعة. وتلخيص الأفكار والأعمال التطوعية المطروحة وتقييمها . دورالمسترشدين (أفراد المجموعة التجريبية)

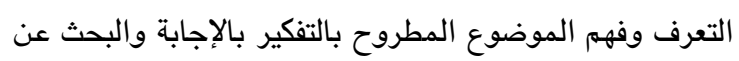

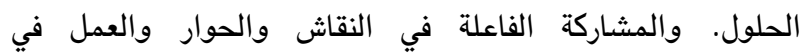
المجموعة . وتقييم الجلسات.

المدة الزمنية لتنفيذ البرنامج

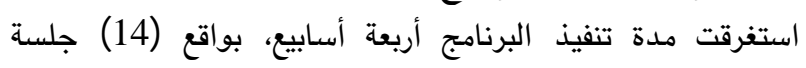
إرشادية جماعية، مدة كل جلسة (60) دقيقة البرنة أسعابع،

جدول (3) : جلسات البرنامج

\begin{tabular}{|c|c|c|c|c|}
\hline 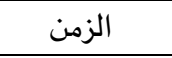 & الأسبوع & جلسات البرمجة اللغوية العصبية & الأسلوب الإرشادي الجمعي & 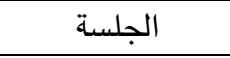 \\
\hline ساعة ونصف & 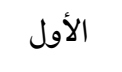 & التعارف + تطبيق أداتي الدراسة للقياس القبلي & التقديم والثرح للبرنامج & الجلسة التمهيدية \\
\hline ساعة واحدة & الأول & مهارات اتصال الشخص بذاته & الندوات واللقاء & 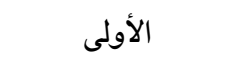 \\
\hline ساعة واحدة & 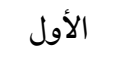 & الإحساس بالذات & الندوات واللقاء & 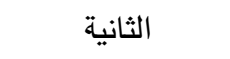 \\
\hline ساعة واحدة & الأول & ق ق الإدراك & الندوات واللقاء الدوري & 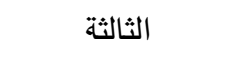 \\
\hline ساعة واحدة & 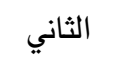 & التحكم في الذات & المناقشة والحوار في مجموعات & الرابعة ابع \\
\hline ثلاث ساعات & الثاني & يوم عمل في مكتبة الجامعة & عمل تطوعي & 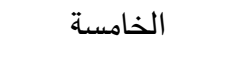 \\
\hline ساعة واحدة & الثاني & ههارات الاتصال بالآخرين & المناقشة والحوار في مجموعات & 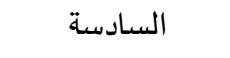 \\
\hline ساعة واحدة & 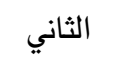 & النظام التمثيلي وأنماط الثخصية والتعلم & المناقشة والحوار في مجموعات & 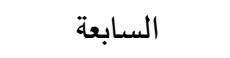 \\
\hline ساعة واحدة & 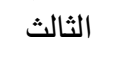 & التأكيدات اللغوية للأنظمة التمثيلية & المناقشة والحوار في مجموعات & 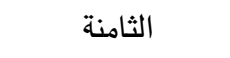 \\
\hline ساعة واحدة & 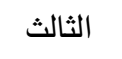 & استراتيجيات بناء العلاقة الإنسانية & التدريب على القيادة & 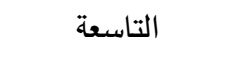 \\
\hline 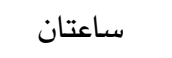 & 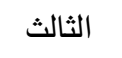 & ورشة عمل في جمعية تعاونية & خدمة المجتمع & 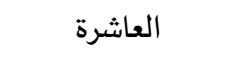 \\
\hline ساعة واحدة & 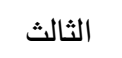 & التفوق في فن الاتصال & الندوات + العروض التقديمية & الحادية عشر \\
\hline ساعة واحدة & 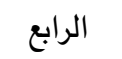 & استراتيجية حل المشكلات & الندوات + العروض التقديمية & الثانية عشر \\
\hline ساعة واحدة & الرابع & استراتيجية الاتصال المطلق & الندوات + العروض التقديمية & 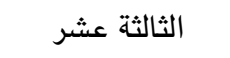 \\
\hline ساعتان & الرابع & محاضرات على مسرح الكلية & التدريب على القيادة & الرابعة عشر \\
\hline ساعة ونصف & الرابع & الشكر + تطبيق أداتي الدراسة للقياس البعدي + + & اللقاء & 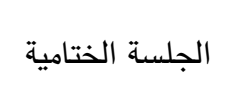 \\
\hline
\end{tabular}

القياسين القبلي والبعدي في مستوى الصفات السلوكية ومهارات

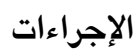
الاتصال اللفظي لغايات الحكم على فاعلية البرنامج.

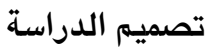

استخدمت الدراسة الحالية التصميم التجريبي،واستخدم فيه

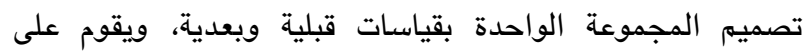

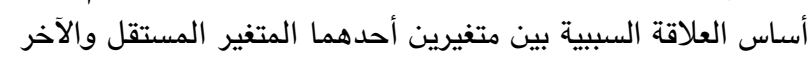

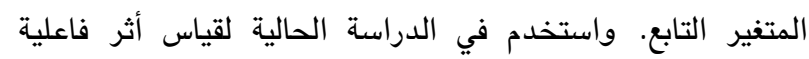

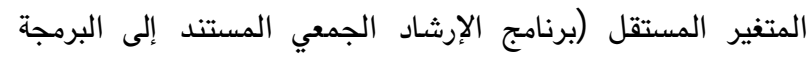

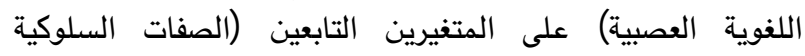

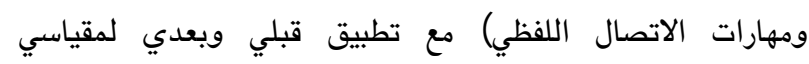
الدراسة. والثكل (1) يوضح تصميم الدراسة.
طبق مقياس الصفات السلوكية ومقياس مهارات الاتصال

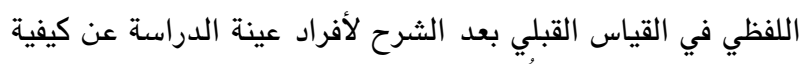

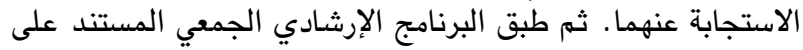

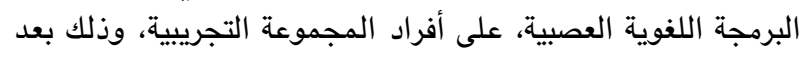

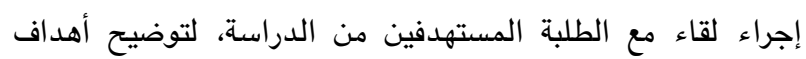

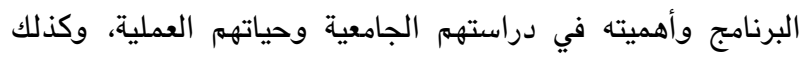

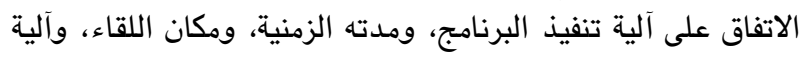

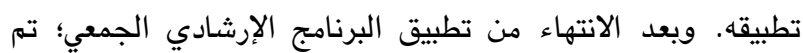

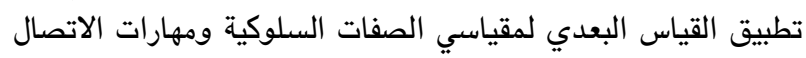

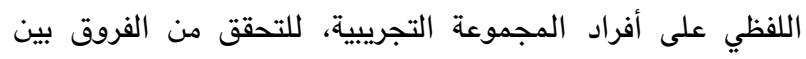


الشكل (1): تصميم الدراسة

المجموعة التجريبية الواحدة

G1

O1

X

$\mathrm{O} 2$

لفحص صحة هذه الفرضية، حُسبت الأوساط الحسابية

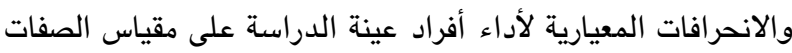

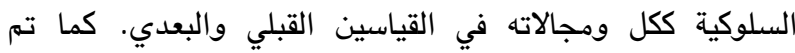

استخدام اختبار ويلكوكسون ) Wilcoxon Signed Ranks (Test

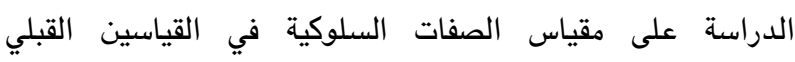
والبعدي، والجدولان (4) و(5) يبينان نتائج ذلك.
وتشير الرموز السابقة التي وردت في الشكل (1) إلى: G1: المجموعة التجريبية، O1: القياس القبلي، O2: القياس البعدي، و X المعالجة (برنامج الإرشاد الجمعي). النتائج أولاً: النتائج المتعلقة بالفرضية الأولى: توجد فروق ذات دلالة

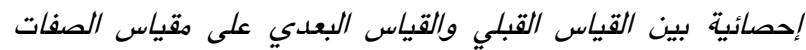

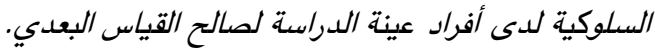

جدول(4): الأوساط الحسابية والانحرافات المعيارية للدرجات على مقياس الصفات السلوكية في القياسين القبلي والبعدي

\begin{tabular}{|c|c|c|c|c|c|}
\hline \multicolumn{2}{|c|}{ البعدي } & \multicolumn{2}{|c|}{ القبلي } & \multirow{2}{*}{ العدد العد } & \multirow{2}{*}{ المجالات والأداة ككل } \\
\hline الانحراف المعياري & الوسط الحسابي & الانحراف المعياري & الوسط الحسابي & & \\
\hline 0.174 & 2.79 & 0.381 & 2.02 & 12 & الصفات الإبداعية \\
\hline 0.273 & 2.83 & 0.370 & 1.98 & 12 & الصفات القيادية \\
\hline 0.368 & 2.84 & 0.340 & 2.06 & 12 & الصفات الدافعية \\
\hline 0.395 & 2.83 & 0.274 & 1.74 & 12 & الصفات التعلمية \\
\hline 0.230 & 2.82 & 0.253 & 1.95 & 12 & الصفات السلوكية ككل \\
\hline
\end{tabular}

يلاحظ من الجدول (4) وجود تباين ظاهري في الأوساط الحسابية لأداء أفراد عينة الدراسة على مقياس الصفات السلوكية ككل ومجالاته بين القياسين القبلي والبعدي. جدول (5): نتائج اختبار ويلكوكسون (Wilcoxon Signed Ranks Test) لدلالة الفروق بين أوساط الرتب لدرجات أفراد عينة الدراسة على مقياس الصفات السلوكية في القياسين القبلي والبعدي

\begin{tabular}{|c|c|c|c|c|c|c|}
\hline الدلالة الاحصائية & Z & مجموع الرتب & وسط الرتب & العدد & الرتب & مجالات الصفات السلوكية \\
\hline \multirow[t]{4}{*}{.002} & -3.063 & .00 & .00 & 0 & الرتب السالبة & \multirow{4}{*}{ الصفات الإبداعية بعدي - الصاعية قبلي } \\
\hline & & 78.00 & 6.50 & 12 & الرتب الموجبة & \\
\hline & & & & 0 & الرتب المتساوية & \\
\hline & & & & 12 & المجموع & \\
\hline \multirow[t]{4}{*}{.002} & -3.063 & .00 & .00 & 0 & الرتب السالبة & \multirow{4}{*}{ الصفات القيادية بعدي - القيادية قبلي } \\
\hline & & 78.00 & 6.50 & 12 & الرتب الموجبة & \\
\hline & & & & 0 & الرتب المتساوية & \\
\hline & & & & 12 & المجموع & \\
\hline \multirow[t]{4}{*}{.002} & -3.065 & .00 & .00 & 0 & الرتب السالبة & \multirow{4}{*}{ الصفات الدافعية بعدي - الصعية قبلي } \\
\hline & & 78.00 & 6.50 & 12 & الرتب الموجبة & \\
\hline & & & & 0 & الرتب المتساوية & \\
\hline & & & & 12 & المجموع & \\
\hline \multirow[t]{4}{*}{.003} & -2.940 & .00 & .00 & 0 & الرتب السالبة & \multirow{4}{*}{ الصفات التعلمية بعدي - التعلمية قبلي } \\
\hline & & 66.00 & 6.00 & 11 & الرتب الموجبة & \\
\hline & & & & 1 & الرتب المتساوية & \\
\hline & & & & 12 & المجموع & \\
\hline
\end{tabular}


حمادنة و القحطاني

\begin{tabular}{|c|c|c|c|c|c|c|}
\hline الدلالة الاحصائية & $\mathrm{Z}$ & مجموع الرتب & وسط الرتب & العدد العد & الرتب & مجالات الصفات السلوكية \\
\hline \multirow[t]{4}{*}{.002} & -3.064 & .00 & .00 & 0 & الرتب السالبة & \multirow{4}{*}{ بعدي - الصفات السلوكية ككل السلوكية } \\
\hline & & 78.00 & 6.50 & 12 & الرتب الموجبة & \\
\hline & & & & 0 & الرتب المتساوية & \\
\hline & & & & 12 & المجموع & \\
\hline
\end{tabular}

تنمية الصفات السلوكية لدى الطلاب المتفوقين في كلية التربية

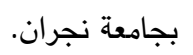

كما تم حساب حجم الأثر للبرنامج الإرشادي الجمعي المستند إلى البرمجة اللفوية العصبية باستخدام معادلة حجم الأثر، الأبري

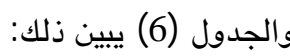
يتضح من الجدول (5) وجود فروق ذات دلالة إحصائية في

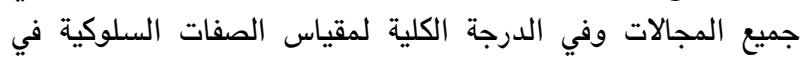
القياسين القبلي والبعدي، وجاءت الفراتي التروق لصالح القية القياس البعدي.

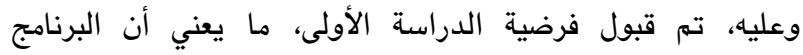
الإرشادي الجمعي المستند إلى البرمجة اللغوية العصبية له أثر في البراني جدول (6): حجم الأثر للبرنامج الإرشادي الجمعي المستند إلى البرمجة اللغوية العصبية على مقياس الصفات السلوكية

\begin{tabular}{|c|c|c|c|c|}
\hline مستوى حجم الاثر & حجم الاثر & قيمة Z & المجال & ت \\
\hline مرتفع & 0.62 & 3.063 & المجال الأول: الصفات الابداعية & 1 \\
\hline مرتفع & 0.63 & 3.065 & المجال الثاني: الصفات القيادية & 2 \\
\hline 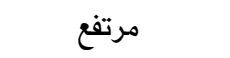 & 0.63 & 3.068 & المجال الثالث: الصفات الدافعية & 3 \\
\hline مرتفع & 0.62 & 3.064 & المجال الرابع: الصفات التعلمية & 4 \\
\hline مرتفع & 0.62 & 3.061 & الاداة ككل & \\
\hline
\end{tabular}

لفحص صحة هذه الفرضية، حُسبت الأوساط الحسابية والانحرافات المعيارية لأداء أفراد عينة الدراسة على مقياس مهارات

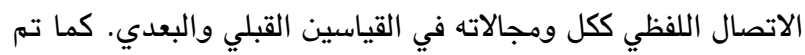

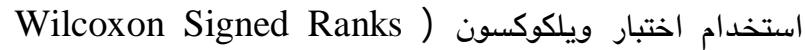
Test

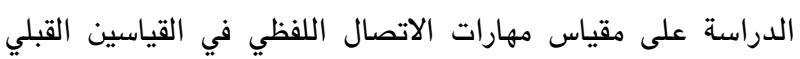
والبعدي، والجدولان (7) و (8) يبينان نتائج ذلك.
يبين الجدول (6) أن البرنامج الإرشادي الجمعي المستند إلى كاعلى

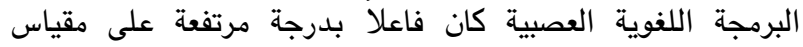
الصفات السلوكية لدى الطلاب المتفوقين (المجموعة التجريبية)

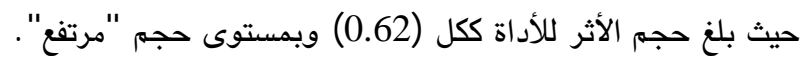
كما كان لمجالات مقياس الصفات السلوكية بمستوى حجم مرتفع. ثانيا: النتائج المتعلقة بالفرضية الثانية: توجد فروق ذات

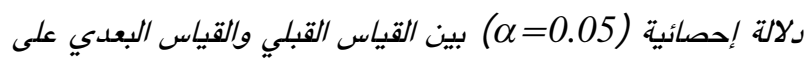

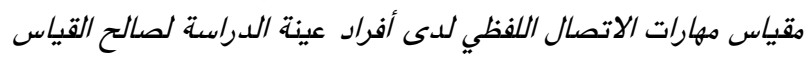

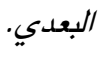
جدول (7): الأوساط الحسابية والانحرافات المعيارية للدرجات على مقياس مهارات الاتصال اللفظي في القياسين القبلي والبعدي

\begin{tabular}{|c|c|c|c|c|c|}
\hline \multicolumn{2}{|c|}{ 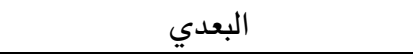 } & \multicolumn{2}{|c|}{ القبلي } & \multirow{3}{*}{ 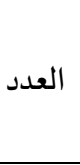 } & \multirow{3}{*}{ المجالات والدرجة الكلية } \\
\hline \multirow{2}{*}{ الانحراف المعياري } & الوسط & الانحراف & الوسط & & \\
\hline & الحسابي & المعياري & الحسابي & & \\
\hline 0.257 & 2.71 & 0.192 & 1.94 & 12 & التحدث \\
\hline 0.347 & 2.79 & 0.454 & 1.92 & 12 & القراءة \\
\hline 0.223 & 2.70 & 0.246 & 1.92 & 12 & الكتابة الك \\
\hline 0.363 & 2.70 & 0.280 & 1.82 & 12 & الاستماع \\
\hline 0.166 & 2.72 & 0.229 & 1.90 & 12 & مهارات الاتصال اللفظي الكلي \\
\hline
\end{tabular}

يلاحظ من الجدول (7) وجود تباينُ ظاهري في الأوساط الحسابية لأداء أفراد عينة الدراسة على مقياس مهارات الاتصال اللفظي ككل ومجالاته في القياسين القبلي والبعدي. 
جدول (8): نتائج اختبار ويلكوكسون (Wilcoxon Signed Ranks Test) لدلالة الفروق بين أوساط الرتب لدرجات أفراد عينة الدراسة على مقياس مهارات الاتصال اللفظي في القياسين القبلي والبعدي

\begin{tabular}{|c|c|c|c|c|c|c|}
\hline الدلالة الاحصائية & $\mathrm{Z}$ & مجموع الرتب & وسط الرتب & 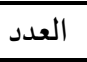 & الرتب & المجالات والدرجة الكلية \\
\hline \multirow[t]{4}{*}{.002} & -3.075 & .00 & .00 & 0 & الرتب السالبة & \multirow{4}{*}{ التحدث التحدي } \\
\hline & & 78.00 & 6.50 & 12 & الرتب الموجبة & \\
\hline & & & & 0 & الرتب المتساوية & \\
\hline & & & & 12 & المجموع & \\
\hline \multirow[t]{4}{*}{.002} & -3.066 & .00 & .00 & 0 & الرتب السالبة & \multirow{4}{*}{ القراءة بعدي } \\
\hline & & 78.00 & 6.50 & 12 & الرتب الموجبة & \\
\hline & & & & 0 & الرتب المتساوية & \\
\hline & & & & 12 & المجموع & \\
\hline \multirow[t]{4}{*}{.002} & -3.065 & .00 & .00 & 0 & الرتب السالبة & \multirow{4}{*}{ الكتابة قبلية } \\
\hline & & 78.00 & 6.50 & 12 & الرتب الموجبة & \\
\hline & & & & 0 & الرتب المتساوية & \\
\hline & & & & 12 & المجموع & \\
\hline \multirow[t]{4}{*}{.003} & -2.943 & .00 & .00 & 0 & الرتب السالبة & \multirow{4}{*}{ الاستماع بعدي } \\
\hline & & 66.00 & 6.00 & 11 & الرتب الموجبة & \\
\hline & & & & 1 & الرتب المتساوية & \\
\hline & & & & 12 & المجموع & \\
\hline \multirow[t]{4}{*}{.002} & -3.062 & .00 & .00 & 0 & الرتب السالبة & مهارات الاتصال اللفظي الكلي \\
\hline & & 78.00 & 6.50 & 12 & الرتب الموجبة & بعدي \\
\hline & & & & 0 & الرتب المتساوية & \multirow{2}{*}{ مهارات الاتصال اللفظي الكلي . } \\
\hline & & & & 12 & المجموع & \\
\hline
\end{tabular}

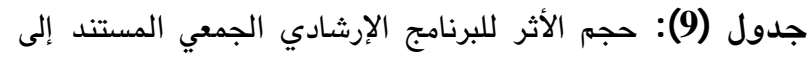

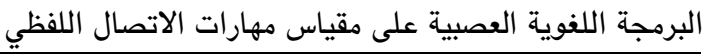

\begin{tabular}{|c|c|c|c|c|}
\hline مجم الاثر & الاثر & قيمة Z & المهارة & ت \\
\hline مرتفع & 0.63 & 3.075 & التحدث & 1 \\
\hline مرتفع & 0.62 & 3.066 & القراءة & 2 \\
\hline مرتفع & 0.62 & 3.065 & الكتابة & 3 \\
\hline مرتفع & 0.60 & 2.943 & الاستماع & 4 \\
\hline مرتفع & 0.62 & 3.062 & الاداة ككل & \\
\hline
\end{tabular}

يبين الجدول (9) وجود أثر للبرنامج الإرشادي الجمعي

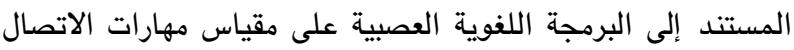

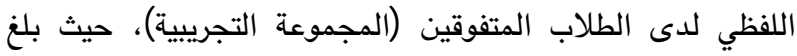

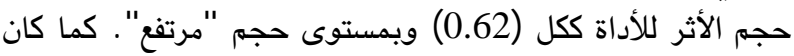

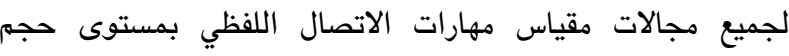
"مرتفع" .
يتضح من الجدول (8) وجود فروق ذات دلالة إحصائية (م)

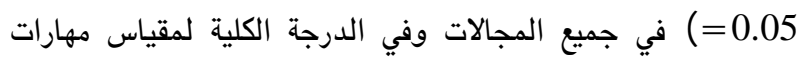

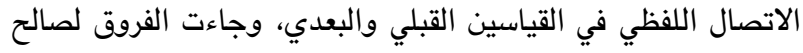

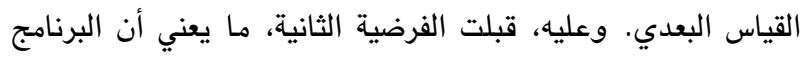

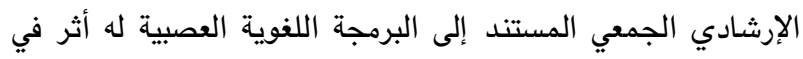
تنمية مهارات الاتصال اللفظي لدى الطلبة المتفوقين في كلية التربية الكراية

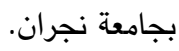
كما تم حساب حجم الأثر للبرنامج الإرشادي الجمعي المستند إلى البرمجة اللغوية العصيية باستخدام معادلة حجم الأثر،

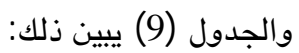


على زيادة ثقة الطلبة بأنفسهم من خلال تدرييهم على كيفية إلقاء

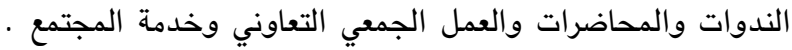

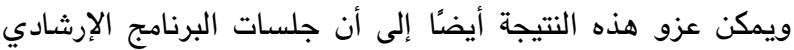

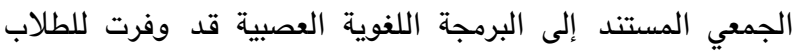

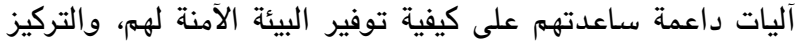

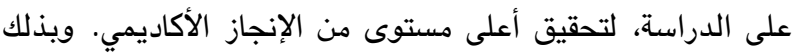

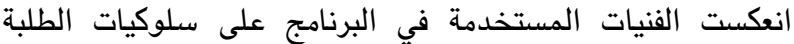

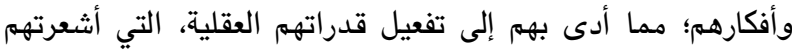

بالثقة بالنفس والوعي بأنفسهم وكيفية استثمار صفاتهم السلوكية.

وتؤكد هذه النتيجة أن البرمجة اللغوية العصبية المقدمة في

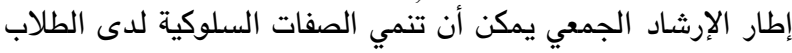

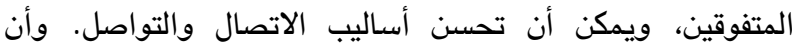

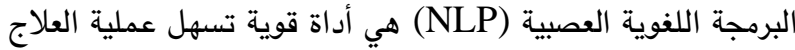

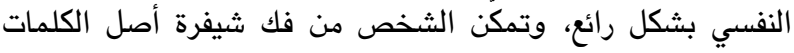

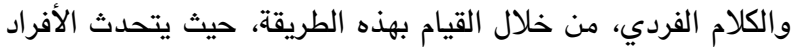

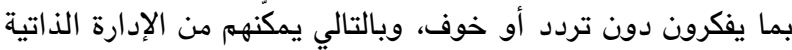

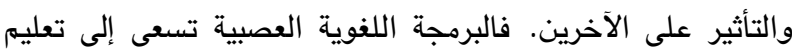

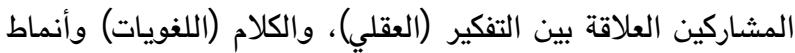
السلوك (Bandler \& Grinder, 2011).

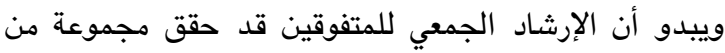

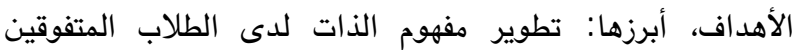

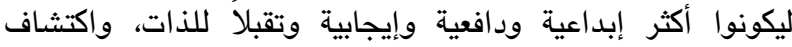
عناصر القوة والضعف لديهم والعمل على تطويرها. بالإضافة إلى إلى

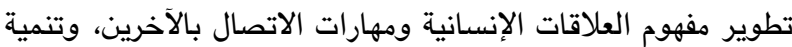

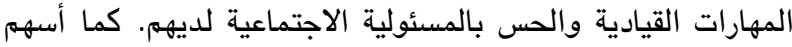

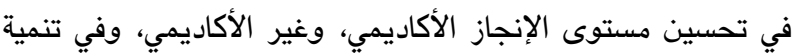

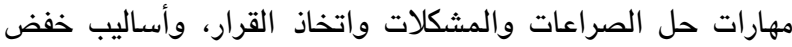

الاضطرابات النفسية كالقلق والتوتر والضغوط النفسية وغيرها .

كما أظهرت نتائج الفرضية الثانية للدراسة وجود فروق ذات دلالة إحصائية في جميع المجالات وفي الدرجة الكلية لمقياس مهارات

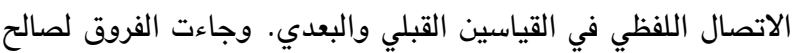

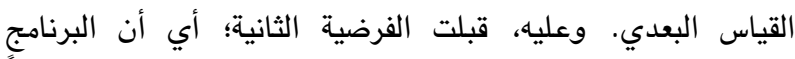

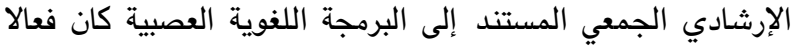

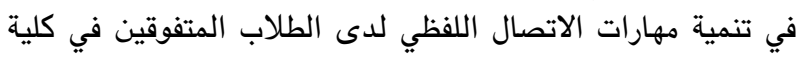

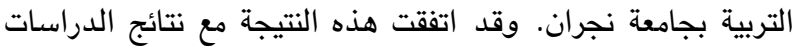

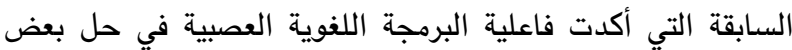

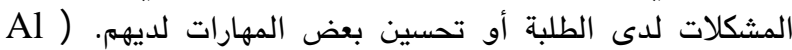
Farah, Bawalsah, \& Al Khateeb, 2016; Al Mamoury, 2017; Al Waleel, 2016; Abdulrahman, 2018; Abu El-Enein\&AbdAlnabi, 2018; Bdaiwi\& Hussein, 2013; Assaleyyeh\& Al Bnna, 2011; Awad, 2016; Bdaiwi\& Hussein, 2013;Fakehy, \& ،(Haggag, 2016; Salami, 2015; Yousef, 2015
مناقشة النتائج

أظهرت نتائج فحص الفرضية الأولى وجود فروق ذات دلالة

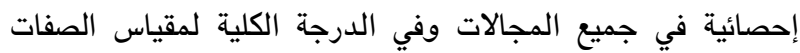

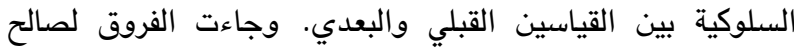

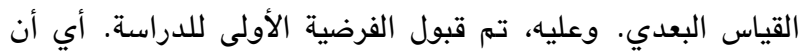

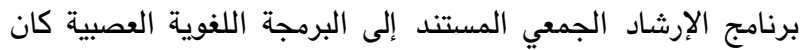

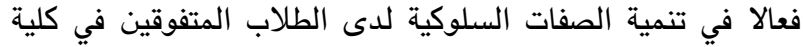
التربية بجامعة نجران.

وقد اتفقت النتيجة الحالية مع نتائج الدراسات السابقة التي كثفت فاعلية برامج الإرشاد الجمعي المستندة للبرمجة اللغوية العصبية (NLP)، في تحسين مؤشرات الصحة النفسية والأداء Al Farah, Bawalsah, \& Al Khateeb, ) النفسي الإجتماعي فيرات 2016; Al Mamoury, 2017; Al Waleel, 2016; Abdulrahman, 2018; Assaleyyeh\& Al Bnna, 2011; Awad, 2016; Abu El-Enein\&AbdAlnabi, 2018; Bdaiwi\& Hussein, 2013; Fakehy, \&Haggag, 2016;

.(Salami, 2015; Yousef, 2015

ويمكن تفسير هذه النتيجة على أساس طبيعة البرنامج

الإرشادي المستخدم الذي وظفّ تكنيكات البرمجة باللفة العصبية

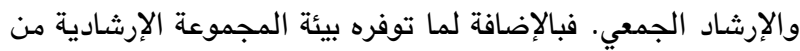
مشاركة وتقبل وشعور بالأمن والثقة، ضمن عمليات المجموعة، من المناء خلال الكثف عن الذات ويناء العلاقة من منظور (NLP)، فقد وند

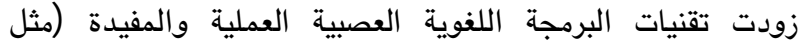
تحديد الأهداف والنظام التمثيلي، والمستويات العصبية) أفراد التوديه المجموعة التجريبية بمهارات مفيدة في التعرف على صفاتهم السلوكية. إذ تؤثر فنيات الإرشاد الجمعي في صحة الأفراد النفسية، وتجعلهم قادرين على التوافق والتكيف مع مواقف الحياة المختلفة.

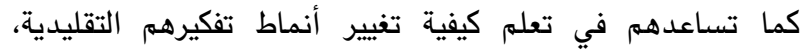

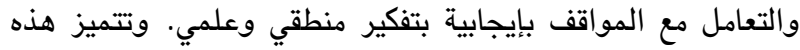

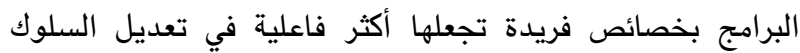
وتطوير الاتجاهات وتنمية مهارات الاتصال الاجتماعية والأكاديمية

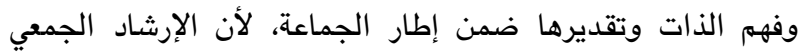
يركز على خبرات أفراد المجموعة ومواقفهم إزاء القضية المطروحة. وقد يكون في المجموعة من هو أقدر من المرشد على استجرار

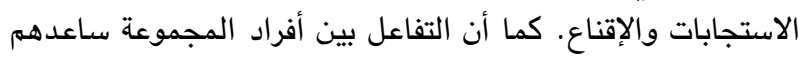

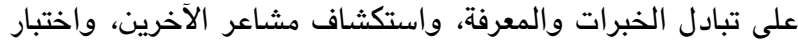

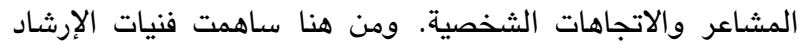

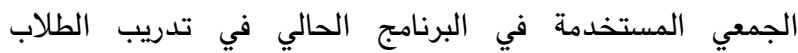
المتفوقين على كيفية التعامل مع موقف الحياة الجامعية المختلفة وكيفية التفلب على الصعويات التي تواجههم، وفي تحسين صفاتهم السلوكية كالإبداعية والقيادية والدافعية والتعلمية.

ويمكن أن تنسب هذه النتيجة أيضًا إلى الفنيات المستخدمة

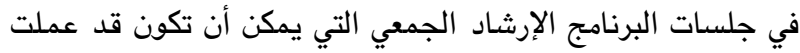




\section{References}

Abdel Wahab, T. (2010). The effectiveness of group psychological therapy in reducing test anxiety among university students at Nazwa University. Journal of Psychology, 23, 30-54.

Abdulrahman, S. (2018). The effect of a training program based on NLP in self-management among students with university learning disabilities. Journal of Faculty of Education, 178(2), 631-691.

Abu Al Nsser, M. (2015). Effective communication skills. Cairo: Arab Group for Training \& Publications.

Abu Asa'ad, A. (2011). Counseling of the gifted and talented. Amman: Dar Al Maseera.

Adam, A. (2013). Communication skills: Theory and practice. Al Riyadh: Dar Al Rushed Publications.

Akacan, B., \& Secim, G. (2015). Social anxiety experiences and responses of university students. Cypriot Journal of Educational Sciences, 10(3), 257-264.

Al Ashqar, W. (2008). The accomplishment level of communication skills among Jordanian university students. Journal of Faculty of Education, 32(2), 463-487.

Al Awwawi, E. (2004). The effect of a counseling program on reducing test anxiety among female third secondary school gradescientific track at Sana'. MA Thesis, Sana' University, Sana', Yemen.

Al Farah, J., Bawalsah, J., \& Al Khateeb, B. (2016). The effectiveness of a program based on neuro-linguistic programming (NLP) in the development of social communication for the gifted sixth grade students in Amman. International Journal of Education, 8(1), 162180.

Al Khawaja, A. (2012). The effectiveness of a group counseling program on reducing test anxiety among a sample of male talented and gifted students at Sultan Qaboos University. Journal of Educational \& Psychological Sciences, 14(3), 471-494.

Al Rehani, S., Al Zraiqat, I., \& Tanous, A. (2010). Counseling students with special needs and their families. Amman: Dar Al Fiker Publications.

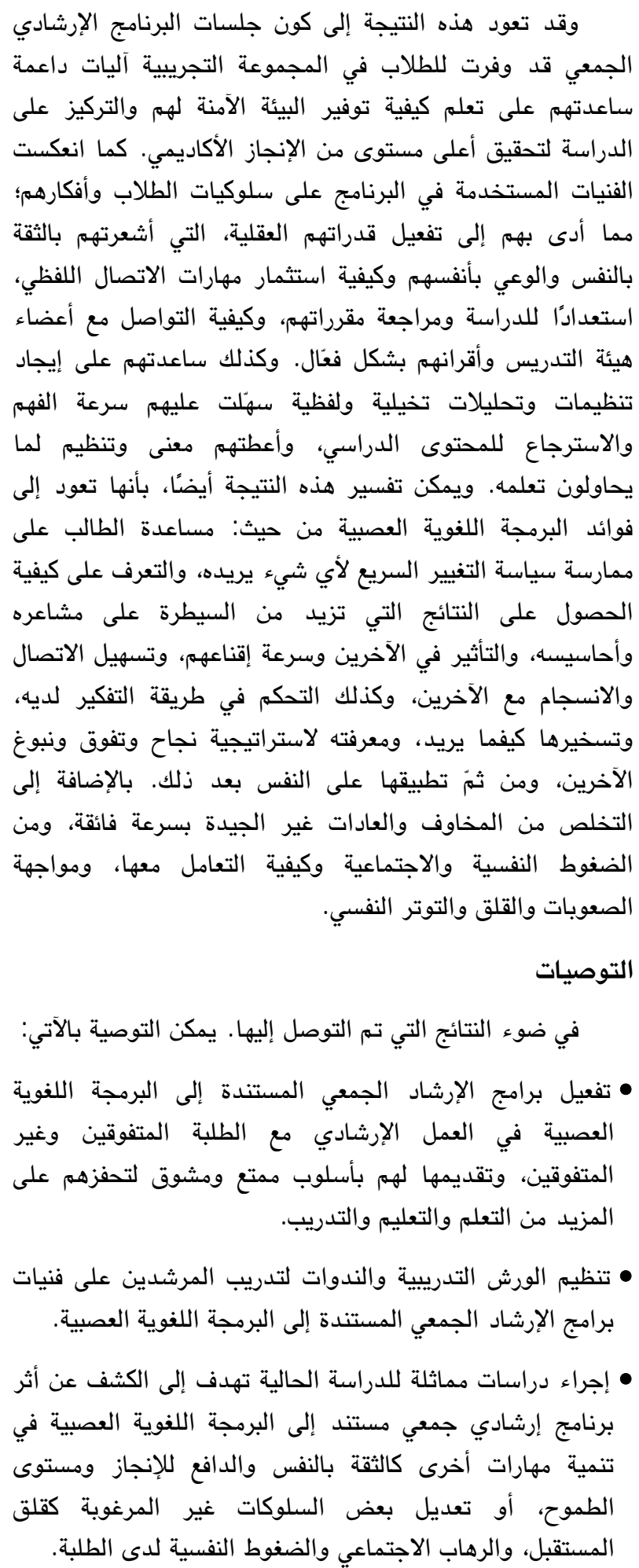


Al Safasfeh, M, (2011). The effect of a group counseling program in developing social selfconcept among a sample of Muta' University students. Jordan Journal of Social Sciences, 4(1), 116-132.

Al Sayyed, S. (2010). The effectiveness of using task based learning (TBL) on Saudi secondary school students acquisition of verbal communication skills in biology course. Journal of Scientific Education, 13(5), 1-41.

Al Shahat, M., \& Al Ballah, K. (2013). The effectiveness of a counseling program in reducing test anxiety and developing selfconfidence and achievement motivation among university students. Journal of Faculty of Education at Banha University, 94(1), 207267.

Al Shlewi, B. (2011). Study skills and their relationship with academic achievement and metacognition skills among a sample of female students at Al Taief University. Unpublished MA.Thesis, Al Taief University, Al Taief, Kingdom of Saudia Arabia.

Al Waleeli, I. (2016). The effectiveness of a neuro linguistic programming based training program on developing achievement motivation among underachieving university students. Journal of Special Education, 14, 239-312.

Alfiky, I. (2009). Neurolinguistic programming and the unlimited communication art. Cairo: Dar Al Raya Publications.

Ali, A. (2002). The effect of using a counseling program on developing some study skills among faculty of education female students at Mecca. Journal of Psychology, 62, 32-49.

Alroudhan, H. (2018). The effect of neurolinguistic programming coaching on learning english. International Journal of Applied Linguistics \& English Literature, 7(4),184190.

Amodeo, A., Picariello, S.,Valerio, P.,Bochicchio, V., \& Scandurra, C. (2017). Group psychodynamic counseling with final-year undergraduates in clinical psychology: A clinical methodology to reinforce academic identity and psychological well-being. Psychodynamic Practice, 23(2), 161-180.
Assaleyyeh, M., \& Al Bnna, A. (2011). The effectiveness of a neurolinguistic programming counseling program on reducing future anxiety among Al Aqsa University students enrolled in political organizations at Gaza Governorate. Journal of Al-Najah University for Human Sciences, 25(5), 11191158.

Awad, M. (2016). The effectiveness of mental training using neuro linguistic programming on improving performance in shot putting sport. Scientific Journal of Physical Education \& Sport, 76, 460-486.

Bakheet, M., \& Mustafa, A. (2010). Communication skills. Al Riyadh: Dar Al Rushed Publications.

Banderler, R., \& Grinder, J. (1979). The structure of majic 1: A book about therapy and language. Palo Alto, CA: Science and Behavior Books.

Banderler, R., \& Thomson, G. (2011). The secrets of being happy: The technology of hope, health, and harmony. NY: IM Press.

Bdaiwi, A- R., \& Hussein, R. (2013). The effectiveness of neurolinguistic programming based training program on developing nonverbal communication among a sample of university students. Journal of Social \& Education Studies, 19(3), 535-598.

Cluntun, A-R. (1992). Behavioral characteristics of talented students scale: The adapted version to the Saudi culture of the Renzulli, et al, (1976) scale. Retrieved from: $w w w$. faculty.ksu.edu.sa/cluntunl/ Documents/202004.

Dear, B., Titov, N., Sunderland, M., McMillan, D.,Anderson, T., Lorian, C \& Robinson, E. (2011). Psychometric comparison of the generalized anxiety disorder scale-7 and the penn state worry questionnaire for measuring response during treatment of generalised anxiety disorder. Cognitive Behavior Therapy, 40(3), 216-227.

Dougherty, S. (2007). Academic advising for highachieving college students. Higher Education in Review, 4, 63-82. 
Fakehy, M., \& Haggag, M. (2016). The effectiveness of a training program using Neuro-Linguistic Programming (NLP) to reduce test anxiety in consideration of biological feedback. Internat-ional Journal of Behavioral Research \& Psychology, 4(1), 173177.

Glennen, R., \& Martin, D. (2000). Summer honors academy: A descriptive analysis and suggestions for advising academically talented students. National Academic Advising Association Journal, 20(2), 38-45.

Grinder, J. (1972). On the cycle in syntax. In J. Kimball (Ed.). Syntax and semantics, NY: Academic Press.

Hamadneh, B. (2014). A guide to talent and giftedness. Irbid: Modern World Bookstore.

Hamadneh, B. (2014b). Creative thinking. Irbid: Modern World Bookstore.

Hamadneh, B. (2017). The effectiveness of a group counseling program on reducing test anxiety and improving study habits among a sample of high achievers at the faculty of educationNajran University. Jordan Journal of Educational Sciences, 13(1), 47-60.

Ibn Jahlan, A. (2009). The effectiveness of mathematical communication based training program for mathematics teachers in developing achievement, written and verbal communication among middle school students in Saudi Arabia. Ph.D. Dissertation, Amman Arab University, Amman, Jordan.

Jarwan, F. (2008). Gifted students diagnosis and care. $3^{\text {rd }}$ ed., Amman: Dar Al Fiker.

Jarwan, F. (2012). Talent, excellency and giftedness. $3^{\text {rd }}$ ed., Amman: Dar Al Fiker.

Jeremy, T., \& Fisher, P. (2012). High achieving students and their experience of the pursuit of academic excellence. ISEP International Symposium (March 30-April 1, 2012, pp. 475499). Sky City, Hong Kong.

Mohammad, A. (2006). Giftedness, talent and innovation. Al Riyadh: Dar Al Zahra'.

Passmore, J., \& Rowson, T. (2019). Neurolinguistic programming: A review of NLP research and the application of NLP in coaching. International Coaching Psychology Review, 14(1), 59-69.
Patterson, C. (1981). Theories of counseling and psychotherapy. Part 1. H. Al-Fekhey (Tras.) Kuwait: University of Kuwauit Publication.

Qandeel, R. (2012). Interactive analysis and neuro linguistic programming as an effective counseling approach. Journal of Faculty of Education at Banha University, 23(89), 7599.

Renzulli, J., Smith, L., White, A., Callahan, C., \& Hartman, R. (1976). Scales for rating the behavioral characteristics of superior students. Mansfield, CT: Creative Learning Press.

Sahebalzamani, M. (2014). Efficacy of neurolinguistic programming training on mental health in nursing and midwifery students. Iranian Journal of Nursing and Midwifery Research, 19(5), 503-507.

Salami, S. (2015). Implementating NeuroLinguistic Programming (NLP) in changing students' behavior: Research done at Islamic Universities in Aceh. Jurnal Ilmiah Peuradeun, 3(2), 235-256.

Suleiman, S. (2014). Human communication psychology \& skills. Cairo: Books World.

Yousef, A. (2015). The effectiveness of a neurolinguistic programming (LNP) based training program on reducing stress and future anxiety among pre- service teachers in mental retardation course at Al Qaseem University. Journal of Educational Sciences, 23(4), 303373.

Zaharia, C., Reiner, M., \&Schütz, P. (2015). Evidence-based neuro linguistic psychotherapy: A metaanalysis. Psychiatria Danubina, 27(4), 355-363.

Zaidan, A. (2015). The effectiveness of religious group counseling in developing quality of life among female high achieving students. Journal of Special Education, 4 (13),185-240 . 